\title{
Characteristics of extreme droughts inferred from tree-ring data in the Qilian Mountains, 1700-2005
}

\author{
Yong Zhang ${ }^{1}$, Xuemei Shao ${ }^{1, *}$, Zhi-Yong Yinn ${ }^{2}$, Eryuan Liang ${ }^{3}$, Qinhua Tian ${ }^{4}$, Yan Xu' \\ ${ }^{1}$ Institute of Geographic Sciences and Natural Resources Research, Chinese Academy of Sciences, Beijing 100101, PR China \\ ${ }^{2}$ Department of Marine Science and Environmental Studies, University of San Diego, San Diego, California 92110, USA \\ ${ }^{3}$ Institute of Tibetan Plateau Research, Chinese Academy of Sciences, Beijing 100085, PR China \\ ${ }^{4}$ Chinese Academy of Meteorological Sciences, Beijing 100081, PR China
}

\begin{abstract}
Severe droughts were evaluated using a tree-ring network of 12 chronologies (1700-2005) from the Qilian Mountains on the northeastern Tibetan Plateau. A total of 98 drought years, including 78 moderate, 15 severe, and 5 extreme events, were identified for the past $306 \mathrm{yr}$. Following the starting year of a drought phase, drought commonly continued for 1 to 2 yr. The spatial patterns of moisture conditions in central and eastern China corresponding to 19 major drought years during the period 1700-2000 were grouped into 3 clusters, with one particular pattern showing droughts of nation-wide impact (i.e. 1721, 1928 and 1966). Drought events became more frequent during the 20th century. Moreover, the multi-year event during the late 1920s and early 1930s was the longest in the past 306 yr. As shown by the tree-ring data, this extreme drought event occurred first in the western Qilian Mountains, and then progressed gradually toward the central and eastern parts of the area, culminating in 1928. Comparison with historical documents demonstrates that the climatic information imbedded in the tree-ring network can provide quantitative measures of drought severity and fill the gaps where historical documents are lacking and/or incomplete.
\end{abstract}

KEY WORDS: Tree ring $\cdot$ Drought $\cdot$ Qilian Mountains $\cdot$ Northeastern Tibetan Plateau

Resale or republication not permitted without written consent of the publisher

\section{INTRODUCTION}

Research into past extreme events is very helpful in forecasting and evaluating possible impacts of extreme droughts in the future, making it possible to reduce the risks related to droughts and improve our knowledge of the forcing mechanisms associated with drought occurrence. However, the instrumental data records for many regions are not sufficiently long to enable characterization of extreme droughts occurring once in several decades or even once in a hundred years. Therefore, there is an urgent need to greatly expand the records of drought variability both spatially and temporarily by developing long and accurate proxy records.

Tree-ring widths, which represent the radial growth rates of trees, have been used as an effective proxy of drought history. Tree-ring chronologies originating from multiple sites form a dendroclimatic network, which can potentially be used to study both spatial and temporal patterns of climatic factors in a region (Cook et al. 2004, 2010a, Touchan et al. 2005, St. George et al. 2009). Tree-ring research focused on regional precipitation and moisture variability has recently made considerable progress in semi-arid and arid regions of China (e.g. Zhang et al. 2003, Sheppard et al. 2004, Shao et al. 2005, Liang et al. 2007, 2009, Tian et al. 2007, Li et al. 2008, 2009, 2010, Yin et al. 2008, Fang et al. 2010, Liu et al. 2010, Zhang et al. 2011). Using historical documents and a millennium length tree-ring based reconstruction of precipitation in the Qaidam Basin, Qinghai Province (Shao et al. 2007), Zhang (2010) compared the dry years recorded in historical documents to those events in the tree- 
ring reconstruction, and found that the tree-ring records can be used to fill information gaps in the documentary records for western China. Liang et al. (2006) investigated the extreme drought in the 1920s in northern China based on tree-ring data from multiple areas and demonstrated the potential to identify spatial patterns of large-scale droughts using treering networks. Huang et al. (2010) analyzed extremely severe drought events of the past $2800 \mathrm{yr}$ as inferred from a ring-width chronology for the eastern Qaidam Basin and found that extreme drought events occurred in clusters during some periods but intermittently during others. For example, severe and extreme drought events occurred with high frequencies during the period from the 3rd century to the end of the 4th century, as well as during the period from the mid-15th century to the 19th century. In contrast, the period from the 5th century to the 12th century was characterized by less frequent drought occurrence. By defining the anomalous growth years in 6 ring-width chronologies for the northeastern Tibetan Plateau, Qin et al. (2010) extracted the most extreme climatic events for the period 1450-2006 and mapped the moisture conditions over large parts of China using a proxy based dryness-wetness index for these events. In spite of these achievements, relatively few studies have integrated large-scale investigations of tree-ring networks to examine both the temporal and spatial structures of severe droughts in China (e.g. Liang et al. 2006, 2010, Yang et al. 2010). Moreover, the spatial and temporal evolution patterns of extreme drought events have not been fully investigated.

The main objectives of our study are (1) to develop a new tree-ring network consisting of 12 moisturesensitive tree-ring series obtained from the Qilian Mountains on the northeastern Tibetan Plateau; (2) to investigate the frequency, severity and characteristics of the spatial and temporal evolution patterns of extreme drought events in the study region during the period 1700-2005; and (3) to examine the spatial structure of moisture conditions at the national level corresponding to years of severe droughts in the study region. The overall aim is to improve our understanding of the mechanisms of severe droughts in this region.

\section{MATERIALS AND METHODS}

\subsection{Study area}

The Qilian Mountains $\left(36^{\circ} 30^{\prime}-39^{\circ} 30^{\prime} \mathrm{N}, 9^{\circ} 31^{\prime}-\right.$ $103^{\circ} \mathrm{E}$ ) are located in the northeastern part of the Tibetan Plateau (Fig. 1). The snowpack and glaciers of the Qilian Mountains represent an important water source for the surrounding areas. The climate in the region is arid and semi-arid, and is influenced by both westerlies and Asian monsoons (Gao 1962, Morrill et al. 2003). According to the official survey report for this area (Yang et al. 2008), annual precipitation averages from 200 to $500 \mathrm{~mm}$ and shows a decreasing trend from the southeast to the northwest. Approximately $70 \%$ of annual total precipitation occurs during the months of May through August. The mean annual temperature ranges from 0.2 to $3.6^{\circ} \mathrm{C}$ in the study region and the annual pan evaporation rate ranges from 1569 to $1788 \mathrm{~mm}$. The vegetation types vary showing a typical elevational distribution pattern, including desert vegetation on the foothills and alpine forests and meadows at higher elevations.

\subsection{Tree-ring data}

Twelve tree-ring chronologies from the Qilian Mountains were used in this study. This dataset includes 2 new chronologies in addition to 10 pub-

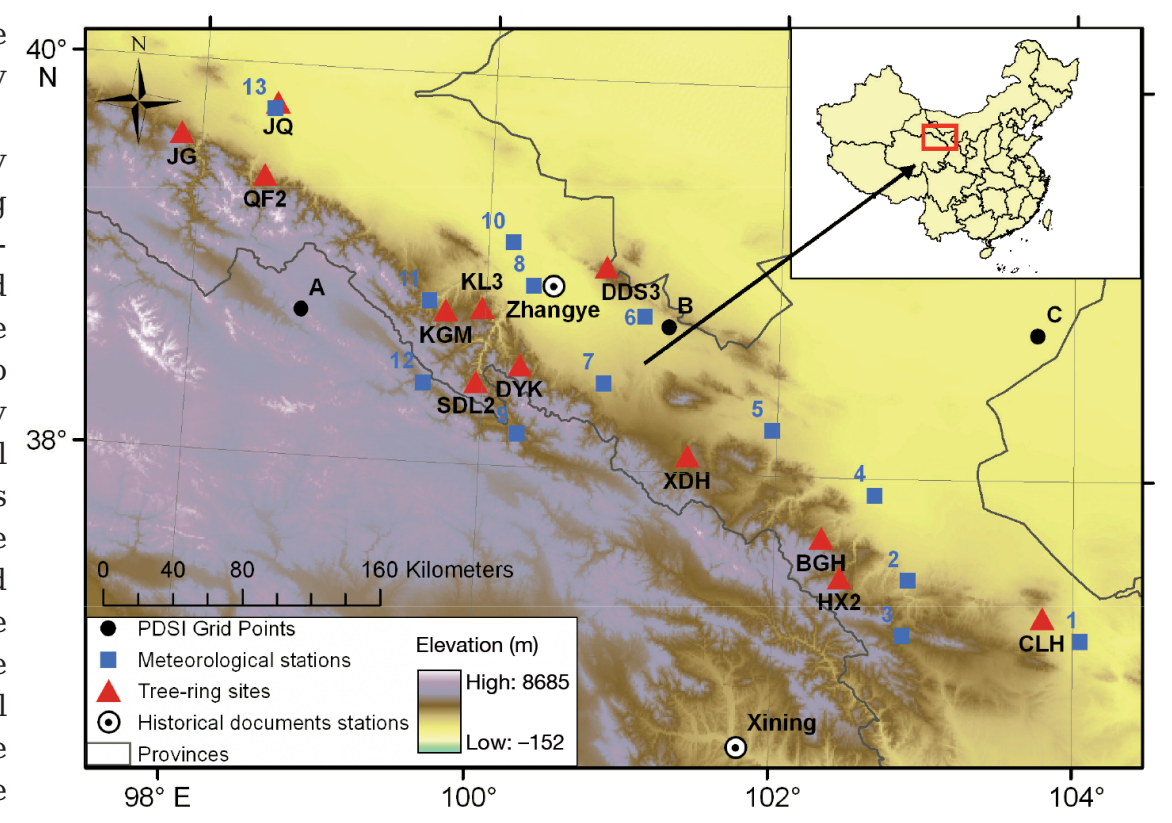

Fig. 1. Locations of the tree-ring sites, meteorological stations, sites described in historical documents (dryness-wetness index, CMA 1981) and Palmer's Drought Severity Index (PDSI) grid points (Cook et al. 2010b) in the study region 
lished chronologies, which were developed specifically for the purpose of this study (Table 1). Each site is identified by a code as shown in Table 1. All of the chronologies were located in the east-central part of the Qilian Mountains along a belt running from northwest to southeast (Fig. 1). The published tree-ring chronologies are for 3 species: Qilian juniper Sabina przewalskii Kom., Qinghai spruce Picea crassifolia Kom., and Chinese pine Pinus tabulaeformis Carr.

The 2 new tree-ring sites, KL3 and DDS3, were located along the lower forest border of the Qilian Mountains, where healthy Qilian junipers Sabina przewalskii Kom. were cored with increment borers. The samples were air dried and then mounted and sanded (Stokes \& Smiley 1968). Ring widths were measured to the nearest $0.001 \mathrm{~mm}$ using a Lintab ring-width measurement system, and were crossdated using the program COFECHA for quality control (Holmes 1983, Grissino-Mayer 2001). To remove the growth trend, a negative exponential or linear function was first fitted to the raw ring-width series. Tree-ring indices were then calculated as the ratio between the measured ring width and the corresponding value of the fitted curve. The tree-ring index series for a given site were averaged together to generate a standard chronology using the program ARSTAN (Cook 1985).

\subsection{Meteorological data and historical documents}

There are 13 meteorological stations located close to our tree-ring sites (Fig. 1, Table 2). All of the sta- tions belong to the national network of first-class meteorological stations maintained by the China Meteorological Administration (CMA). Data from these stations were obtained from the CMA's homogenized climatic dataset (http://new-cdc.cma.gov.cn: 8081/dataSetLogger.do? changeFlag=dataLogger, accessed on July 23, 2011). This dataset has been subjected to rigorous data quality assessment and quality control procedures in which all data with unusual values are screened and then corrected if necessary (CMA 2003).

Several datasets based on historical documents (CMA 1981, Shi 2003, Zhang 2004, Wen 2005) were considered for comparison with and verification of our reconstruction to assess the quality of the climatic information recorded by the tree-rings. Table 3 provides a summary of these datasets. Drought events are qualitatively recorded in descriptive texts in the first 3 documentary sources, while the last document provides quantitative measures of drought and flood events using numerical scales. In addition, we used an updated version of the CMA dataset in which the missing values were in-filled by interpolation (Hao et al. 2009) to analyze the spatial characteristics of moisture conditions in central and eastern China during the study period 1700-2000. This dataset contains the dryness-wetness index data for 120 locations, mostly in central and eastern China, with the values being determined using May-September precipitation data during the calibration period 1951-2000. Drought and flood events were classified into 5 grades (1 to 5), representing climate conditions from severe flood to severe drought.

Table 1. Site description and general characteristics of the 12 standardized tree-ring width chronologies used in this study. Tree species: (PT) Pinus tabulaeformis Carr., (PC) Picea crassifolia Kom., (SP) Sabina przewalskii Kom. SNR: signal-to-noise ratio. The start year is the date from which the data series is considered reliable, i.e. when the expressed population signal (EPS) (Wigley et al. 1984) exceeds the threshold value 0.85. Sources: (1) Gao et al. 2005, (2) Liang et al. 2010, (3) Liang et al. 2006, (4) Tian et al. 2007, (5) Zhang 2009, (6) present study. Tree/core = no. of trees and cores used in the chronologies; mean sensitive $=$ a measure of high-frequency ring width variance (Fritts 1976)

\begin{tabular}{|c|c|c|c|c|c|c|c|c|c|c|c|}
\hline $\begin{array}{l}\text { Site } \\
\text { code }\end{array}$ & $\begin{array}{c}\text { Latitude } \\
\left({ }^{\circ} \mathrm{N}\right)\end{array}$ & $\begin{array}{c}\text { Longitude } \\
\left({ }^{\circ} \mathrm{E}\right)\end{array}$ & $\begin{array}{l}\text { Elevation } \\
(\mathrm{m})\end{array}$ & Period & Tree/core & $\begin{array}{c}\text { Mean } \\
\text { sensitive }\end{array}$ & Species & $\begin{array}{c}\text { Common } \\
\text { period }\end{array}$ & SNR & $\begin{array}{l}\text { Start } \\
\text { year }\end{array}$ & Source \\
\hline $\mathrm{CLH}$ & 37.30 & 103.80 & 2500 & 1639-2002 & $21 / 44$ & 0.404 & $\mathrm{PT}$ & 1900-2002 & 80.9 & 1801 & 1 \\
\hline HX2 & 37.49 & 102.44 & 2826 & $1825-2003$ & $21 / 46$ & 0.301 & SP & $1910-2000$ & 38.1 & 1846 & 2 \\
\hline $\mathrm{BGH}$ & 37.69 & 102.31 & 2000 & 1896-2003 & $33 / 92$ & 0.242 & $\mathrm{PC}$ & $1950-2003$ & 116.3 & 1915 & 2 \\
\hline $\mathrm{XDH}$ & 38.09 & 101.40 & 2755 & 1770-2005 & $22 / 40$ & 0.267 & $\mathrm{PC}$ & 1920-2000 & 57.1 & 1789 & 5 \\
\hline DYK & 38.52 & 100.25 & 3040 & $1780-2005$ & $24 / 32$ & 0.233 & $\mathrm{PC}$ & $1900-2000$ & 14.7 & 1820 & 5 \\
\hline SDL2 & 38.43 & 99.95 & 3370 & $1091-2003$ & $25 / 72$ & 0.229 & SP & $1700-2000$ & 30.1 & 1447 & 2 \\
\hline DDS3 & 39.04 & 100.81 & 2800 & 1484-2005 & $24 / 34$ & 0.489 & $\mathrm{SP}$ & $1850-2000$ & 34.7 & 1613 & 6 \\
\hline KL3 & 38.81 & 99.96 & 3000 & $1300-2005$ & $19 / 37$ & 0.347 & $\mathrm{SP}$ & $1850-2000$ & 24.3 & 1510 & 6 \\
\hline KGM & 38.79 & 99.73 & 2900 & 1848-2005 & $24 / 29$ & 0.251 & $\mathrm{PC}$ & $1950-2000$ & 32.7 & 1861 & 5 \\
\hline QF2 & 39.43 & 98.44 & 3060 & $1729-2003$ & $18 / 52$ & 0.475 & $\mathrm{SP}$ & $1900-2000$ & 55.3 & 1760 & 3 \\
\hline JQ & 39.77 & 98.48 & 2850 & $1780-2001$ & $12 / 27$ & 0.382 & $\mathrm{SP}$ & $1950-2000$ & 29.3 & 1803 & 4 \\
\hline JG & 39.61 & 97.86 & 2852 & $1727-2005$ & $15 / 31$ & 0.295 & $\mathrm{PC}$ & $1950-2000$ & 36.2 & 1830 & 5 \\
\hline
\end{tabular}


Table 2. Information on the 13 meteorological stations used in this study

\begin{tabular}{|c|c|c|c|c|c|c|c|}
\hline $\begin{array}{l}\text { WMO station } \\
\text { numbers }\end{array}$ & Number & Code & Name & $\begin{array}{l}\text { Latitude } \\
\left({ }^{\circ} \mathrm{N}\right)\end{array}$ & $\begin{array}{l}\text { Longitude } \\
\left({ }^{\circ} \mathrm{E}\right)\end{array}$ & Interval & $\begin{array}{c}\text { Elevation } \\
(\mathrm{m})\end{array}$ \\
\hline 52797 & 1 & JT & Jingtai & 37.18 & 104.05 & 1957-2006 & 1631 \\
\hline 52784 & 2 & GL & Gulang & 37.48 & 102.90 & 1959-2006 & 2073 \\
\hline 52787 & 3 & WS & Wushao & 37.20 & 102.87 & $1951-2006$ & 3043 \\
\hline 52679 & 4 & WW & Wuwei & 37.92 & 102.67 & $1951-2006$ & 1532 \\
\hline 52674 & 5 & $\mathrm{YC}$ & Yongchang & 38.23 & 101.97 & 1959-2006 & 1976 \\
\hline 52661 & 6 & SD & Shandan & 38.80 & 101.08 & $1953-2006$ & 1765 \\
\hline 52656 & 7 & ML & Minle & 38.45 & 100.82 & 1958-2006 & 2271 \\
\hline 52652 & 8 & $\mathrm{ZY}$ & Zhangye & 38.93 & 100.43 & 1951-2006 & 1480 \\
\hline 52657 & 9 & QL & Qilian & 38.17 & 100.25 & $1957-2006$ & 2787 \\
\hline 52557 & 10 & $\mathrm{LZ}$ & Linze & 39.15 & 100.17 & $1967-2006$ & 1454 \\
\hline 52643 & 11 & $\mathrm{SN}$ & Sunan & 38.83 & 99.62 & $1957-2006$ & 2311 \\
\hline 52645 & 12 & YN & Yeniugou & 38.40 & 99.60 & $1960-2006$ & 3320 \\
\hline 52533 & 13 & JQ & Jiuquan & 39.77 & 98.49 & $1951-2006$ & 1478 \\
\hline
\end{tabular}

\subsection{Statistical analysis}

Climatic factors affecting the tree-ring width at the new tree-ring sites KL3 and DDS3 were investigated. Monthly temperature and precipitation data from 2 meteorological stations (at Sunan and Zhangye) were used to calculate dendroclimatic correlations with the 2 new ring-width chronologies through a simple correlation analysis. The analysis was performed using climatic data from September of the previous year to August of the current year (12 mo in total) for the periods 1957-2005 and 1951-2005 for Sunan and Zhangye stations, respectively.

According to the original sources (see Table 1), most of the 10 published chronologies were also significantly and positively correlated with monthly precipitation in the early growing season and negatively correlated with monthly temperature in the same months. To verify the impact of early growing season moisture condition on tree growth, all 12 tree-ring series were correlated with the May-June precipitation and temperature time-series as recorded at nearby meteorological stations.

\subsection{Developing a regional tree-ring width index for the Qilian Mountains}

To develop a regional tree-ring network in the reconstruction of drought history, we re-processed the ring-width series at all 12 sites. First, a $32 \mathrm{yr}$ spline function, as described by Grissino-Mayer (2001), was constructed using the ring-width series. The actual ring width for any given year was then divided by the value predicted by the spline function for the same year, resulting in a dimensionless annual index. This procedure should remove lowfrequency signals at decadal ( $16 \mathrm{yr}$ to be exact) and longer scales. In addition, autoregressive modeling was employed to remove any persistence that may remain after the growth variability represented by the spline curve is removed from the measurement series. The resulting residual series at each site were then normalized by using their mean and standard deviation. Thus, we developed 12 standardized series for the Qilian Mountains in which large index values correspond to wide rings, and low values to narrow rings, optimized for high-frequency climatic signals. To represent regional tree growth conditions, these 12 standardized series were combined to form a composite tree-ring width index series by calculating the arithmetic mean for each year. Finally, the composite tree-ring width index series was normalized. The standardized composite tree-ring width index series (hereafter referred to as the TWI) was used to reflect the climate variability in the region. The statistic of the expressed population signal (EPS) (Wigley et al. 1984) was used with a threshold value of 0.85 to determine the period for which each chronology was sufficiently replicated to be deemed reliable.

To evaluate the spatial representation of the 12 standardized series, the composite means of the 12 tree-ring series in prominent drought years during the instrumental data period (i.e. 1962, 1968, 1971, 1974, 1981, 1995 and 2001) were compared spatially with those of normalized precipitation series for the 13 meteorological stations.

To measure spatial variability among the individual tree-ring sites, we counted the number of the standardized series with negative values for each year and used the proportion of the number of the standardized series with negative values as a mea- 


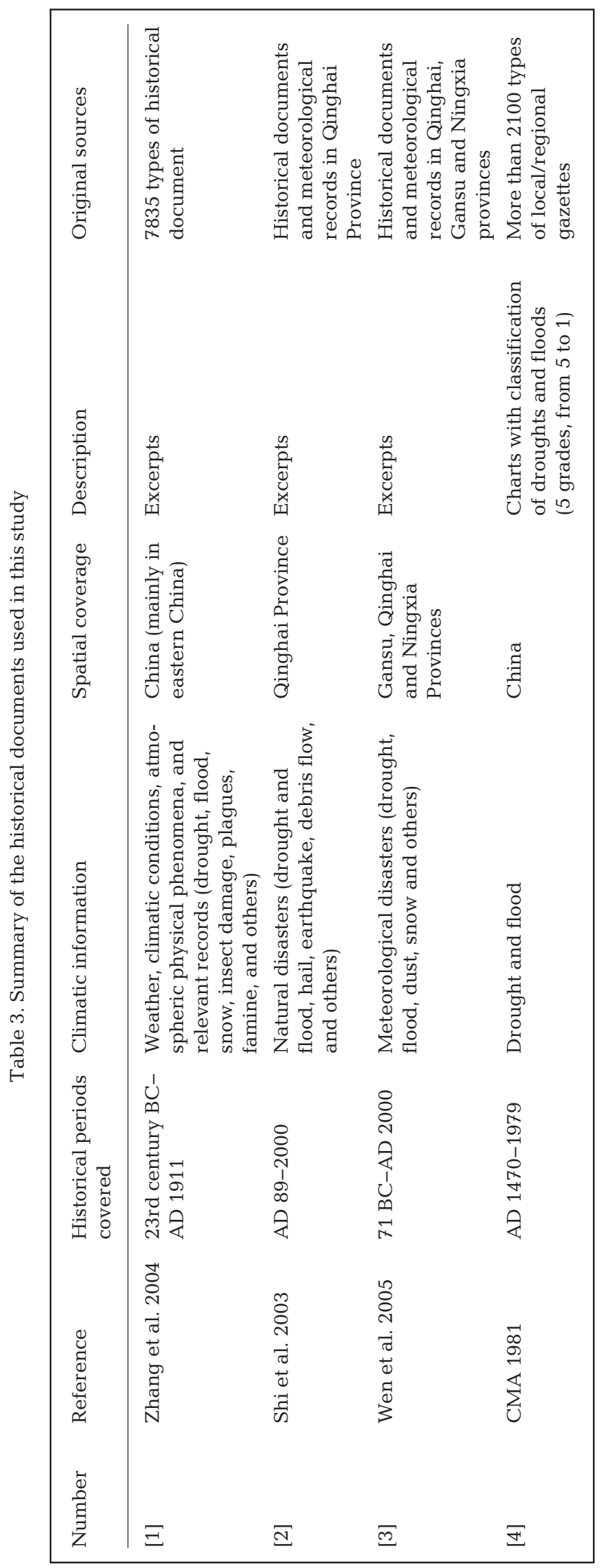

sure of spatial consistency for drought years. We designated this series as the index of spatial consistency (ISC). An ISC value of 1.0 means that all individual tree-ring series exhibited low-growth conditions for that year, while lower values suggest a reduced level of spatial consistency among the tree-ring series as indicators of climate conditions.

Droughts are extended periods of below-normal moisture conditions that have adverse impacts on plants and crops (Dracup et al. 1980). The impacts of droughts can be measured by their intensity and severity, with the latter parameter considering both the intensity and duration (Palmer 1965). In this study, the narrowness of ring-widths was used to represent drought severity in the study region. For analyzing the severity and frequency of droughts, the TWI series was graded based on its mean $(0)$ and standard deviation $(\sigma=1)$. Values between $-0.5 \sigma$ and $-1.5 \sigma$ were defined as moderate droughts (labeled as 1); values between $-1.5 \sigma$ and $-2.5 \sigma$ were considered as severe droughts (labeled as 2); and values below $-2.5 \sigma$ were classified as extreme droughts (labeled as 3). Prior to this classification, the 1-sample K-S test (Conover 1971) was employed to check the normality of the TWI series, thus ensuring the reliability of classification.

\subsection{Cluster analysis}

After the severe and extreme drought years were identified for the study region, we examined the spatial patterns of moisture conditions for all of central and eastern China during those years using cluster analysis.

Cluster analysis is an effective statistical tool for objectively grouping individual members into homogeneous clusters based on certain metrics, and has been widely used in different types of climatological research. In this study, we used an agglomerative hierarchical technique with Euclidian distance (the square root of the sum of the squared distances between all variables) as the distance metric (Jain \& Dubes 1988). In hierarchical clustering analysis, specific measurements of dissimilarity are used to characterize the relationships among the individuals and to search for the most similar pairs to merge. Based on previous studies (Unal et al. 2003, Carnelli et al. 2004, Friedrichs et al. 2009), we chose Ward's method (Ward 1963), in which the criterion for the choice 
of linkage between a pair of individuals is the least increase in the sum of the squared deviations from the cluster means. Most applications of cluster analysis in climatological studies are employed to identify homogeneous spatial zones or locations based on certain climatic attributes (e.g. Stahl \& Demuth 1999, Dezfuli 2011, Fu et al. 2011). However, we used it as a means of temporal-spatial analysis to identify clusters of drought events (years) that exhibited similar spatial patterns in the updated dryness-wetness index dataset (Hao et al. 2009). There were 91 stations/locations in central and eastern China with available data for the study period. Rather than identifying homogenous stations or spatial zones, we attempted to identify groups of years that showed similar spatial structures. Thus, there were initially $\mathrm{N}$ events or members (drought years) that were treated as variables, and each included 91 observations (stations or locations). These events were successively merged in $\mathrm{N}-1$ steps until all events were included as members of a single group. With each progressive step, the within-group variance increased as more members were included in a given cluster. However, Ward's method minimizes increases in the within-group variance (sum of the squared errors). Euclidian distance, rather than correlation, was considered as the distance metric because we were interested in the similarities of absolute measures of drought/wetness. For example, a north-dry, south-wet spatial pattern may be matched with a north-dry, south-wet pattern with minor variations, but not with a north-wet and south-extremely wet pattern. Jain \& Dubes (1988) noted that choosing an appropriate number of classes is a critical, yet frustrating part of cluster analysis. Certain criteria (e.g. those proposed by Dezfuli 2011), although they are subjective, must be defined in accordance with the purpose of the analysis and the characteristics of the data. In our case, the criteria were:

(1) We wanted to avoid a final cluster with only one member, as this reduces the representativeness of the cluster, and preferably have a relatively even distribution of the members in the final clusters.

(2) We set our intended number of clusters as 3 to 5 considering the total number of events and the ease of interpretation.

(3) We wanted to ensure the homogeneity of the clusters as much as possible, which was the main reason for our choice of Ward's method.

(4) Resultant clusters should render spatial patterns that are physically meaningful and relatively easy to interpret.

\section{RESULTS}

\subsection{Climatic implications of the 12 tree-ring chronologies}

Analysis of the relationships between tree growth and climatic factors at the 2 new tree-ring sites KL3 and DDS3 showed some variances between the 2 chronologies for individual months (Fig. 2). Nevertheless, the consistent pattern of highly positive correlations with monthly precipitation during May and June, along with the negative correlations with temperature for the same months, indicated that tree growth at these 2 sites was indeed sensitive to moisture variations, especially in the early growing season. Similar patterns have also been found at other moisture-sensitive sites in the Qilian Mountains, the eastern Qaidam Basin and the Anyemaqen Mountains (Shao et al. 2005, Gou et al. 2007, Liu et al. 2009, Zhang et al. 2011). During the period of cambial activity, sufficient soil moisture must be available for tree growth when evapotranspiration rates are high and the trees are in full vigor. Temperature is a proxy for insolation and has been used as an important factor, or even as the single factor, in calculations of potential evapotranspiration (Xu \& Singh 2002). Additionally, high temperature in the early growing season would enhance the physiological activities of trees, which could create biological water-use stress associated with the limited moisture availability in a semi-arid environment (Fritts 1976). Therefore, the combined pattern of positive correlations with precipitation and negative correlations with temperature in the early growing season is an indicator that tree growth in the study region is moisture-sensitive.

The correlation analysis for all of the tree-ring series with the May-June precipitation and temperature showed that all of the tree-ring series were positively correlated with May-June precipitation, and most of the tree-ring series were negatively correlated with May-June temperature (Fig. 3). The correlation coefficients of the tree-ring series at sites $\mathrm{JG}, \mathrm{BGH}$ and HX2 (see Fig. 1) with May-June precipitation and temperature were relatively low and were not statistically significant at the 0.05 level. However at HX2 and $\mathrm{BGH}$, strong correlations were found between tree growth and the Palmer's Drought Severity Index (PDSI) in May and June (Liang et al. 2010). Furthermore, tree growth at JG showed a strong positive correlation $(\mathrm{r}=0.628)$ with a climate index (described in Barber et al. 2000), which is based on the positive contribution of precipitation and negative influence of temperature during the growing season (Zhang 

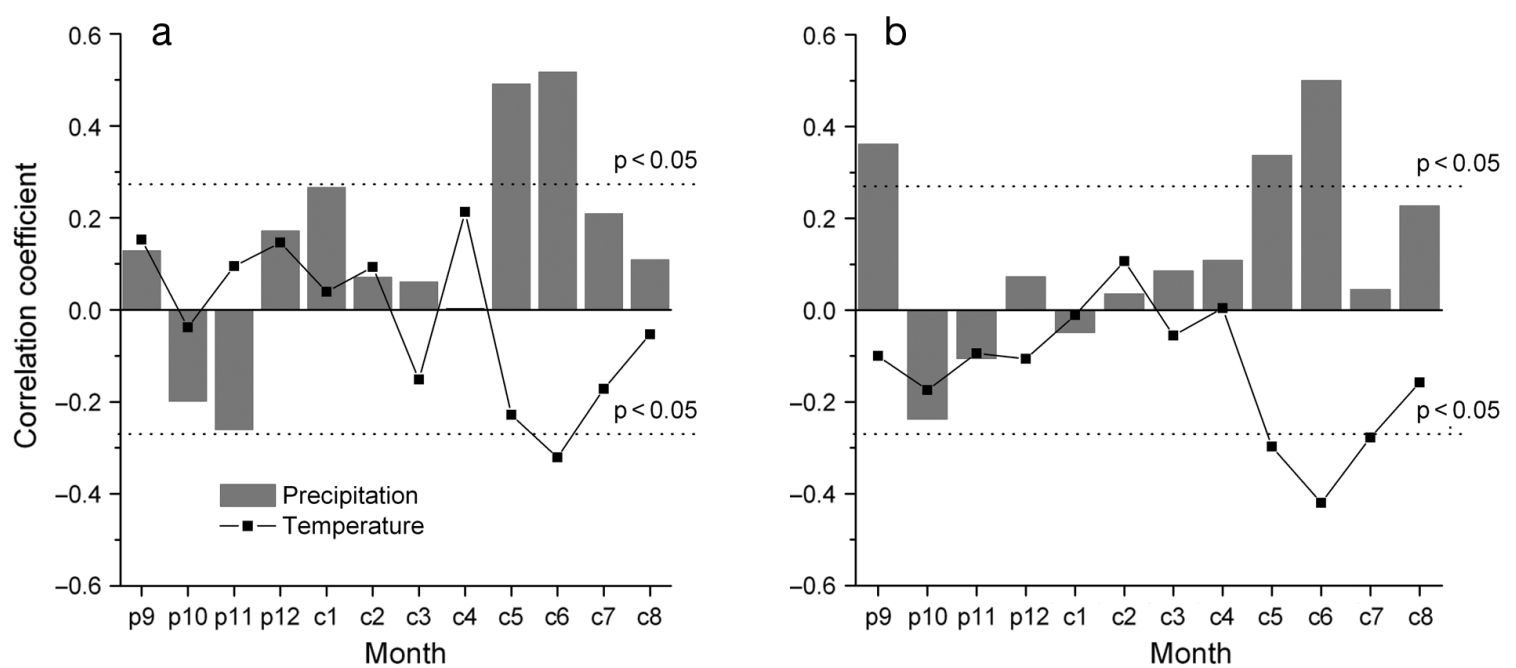

Fig. 2. Correlation coefficients of the tree-ring data from sites (a) KL3 and (b) DDS3 with monthly temperature and precipitation at nearby meteorological stations: (a) Sunan, (b) Zhangye. Months p9 to p12 are previous-year September to December, and c1 to c8 are current-year January to August

2009). Therefore, tree growth at all 12 sites was confirmed to be moisture-sensitive, which allowed us to develop a new tree-ring network for reconstructing the regional drought history and ensured a sufficient sample size and a relatively even spatial distribution of tree-ring sites across the study region.

\subsection{The temporal and spatial features of the new tree-ring network}

Fig. 4 shows the 12 individual standardized chronologies used in this study. According to the EPS

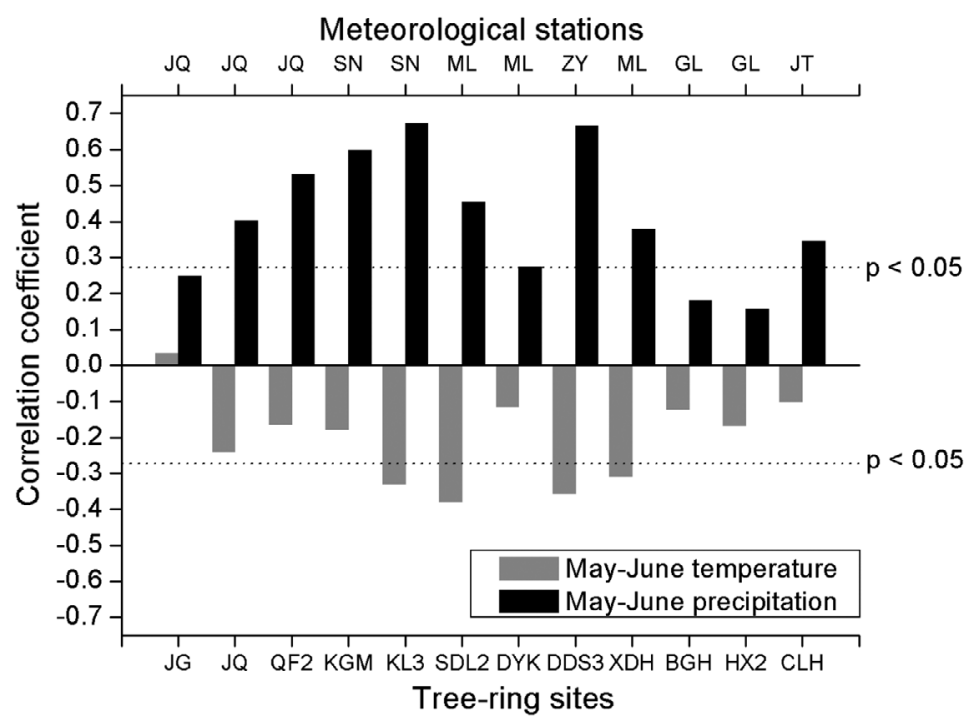

Fig. 3. Correlation coefficients of the 12 tree-ring series used in the study with May-June temperature and precipitation at nearby meteorological stations values for the 12 tree-ring series (Table 1), chronologies for the eastern and western sections of the study region were generally reliable (EPS $\geq 0.85$ ) from the early nineteenth century onwards, whereas chronologies for the middle part of the region were reliable farther back in time, to the seventeenth century. Compared to the instrumental data, the droughts recorded in the tree rings demonstrated a similar spatial pattern over the study area, especially for the middle section where the droughts were most severe (Fig. 5). Good agreement between the drought severity recorded by the tree rings and the instrumental data suggested that this tree-ring network can be used to represent the spatial characteristics and evolution of regional extreme droughts.

Fig. 6a shows the TWI series, in which several large-scale slow-growth years can be identified, such as 1714 (TWI $=-2.78), 1824(-3.01), 1884$ $(-2.65)$ and $1928(-3.16)$, as well as the largescale fast-growth years 1736 (1.87), 1804 (1.82) and 1924 (2.42). Furthermore, the 11 yr moving averages showed fluctuations at the decadal timescale, including the fast-growth period of 1802-1814 and the slow-growth period of 19231936. However, sample depth, i.e. the number of series available in different periods, fluctuated over time (Fig. 6). A decrease in sample depth would reduce the reliability of the TWI series.

The TWI series was then compared to regional May-June precipitation during the period 19552005 (Fig. 7). May-June precipitation at each of the 13 meteorological stations was first normalized based on its long-term mean and standard deviation, and the arithmetic mean for each year 


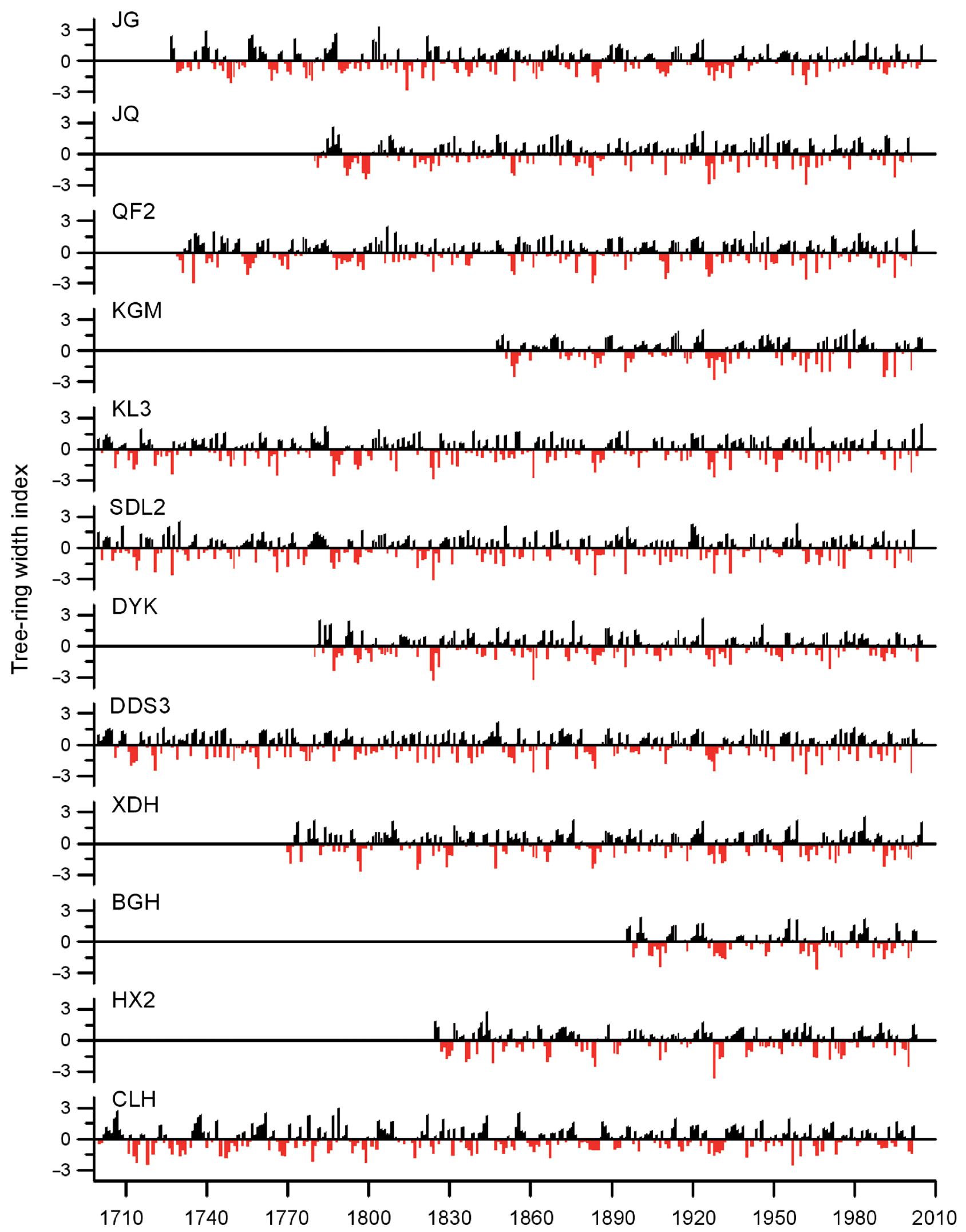

Fig. 4. Standardized tree-ring width series of the 12 sampling sites used in the study. Negative values (red bars) indicate dry conditions and positive values (black bars) indicate wet conditions 


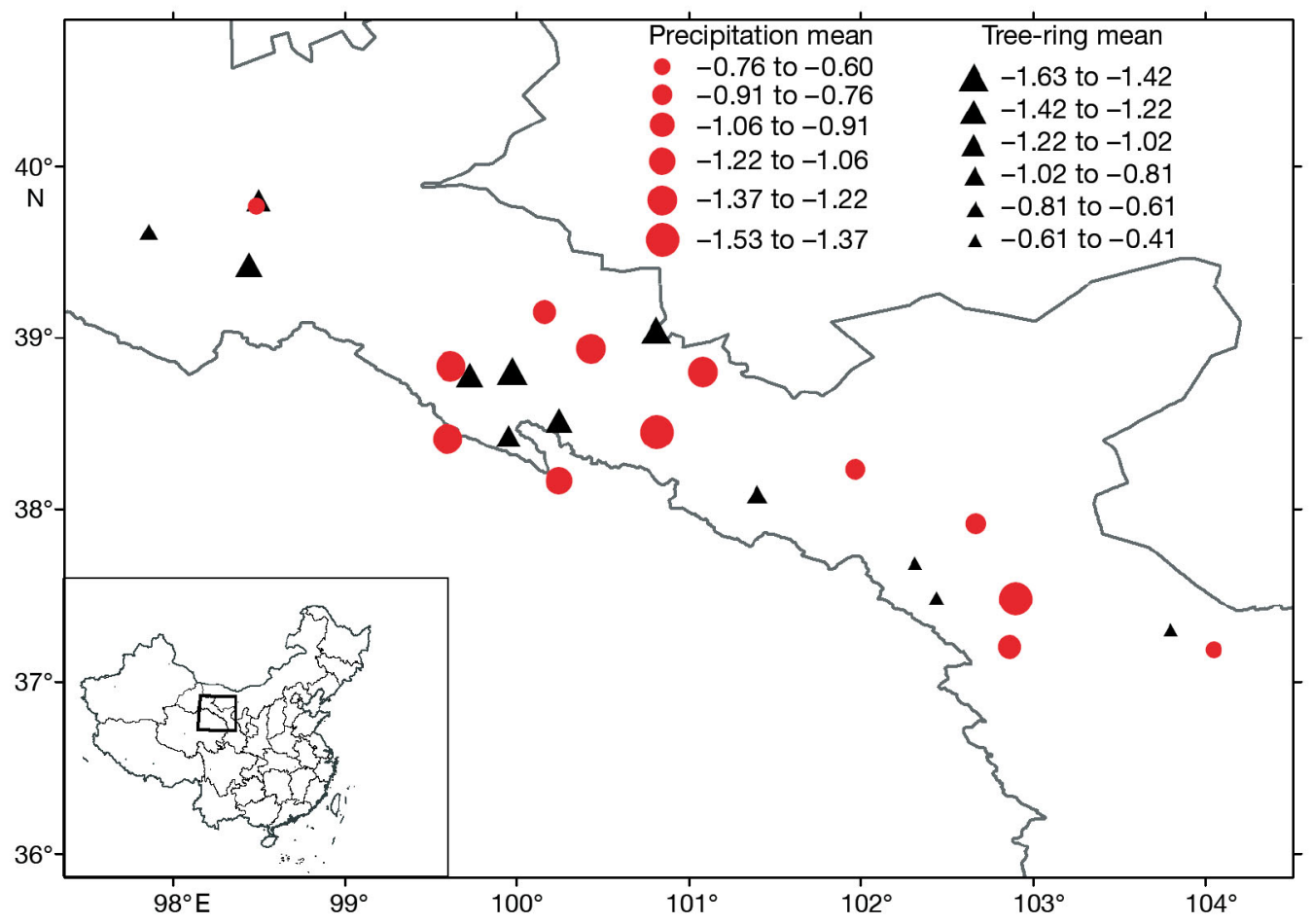

Fig. 5. Comparison between the means of the 12 standardized tree-ring series and those of the 13 standardized series of precipitation at meteorological stations for the prominent drought years 1962, 1968, 1971, 1974, 1981, 1995 and 2001. Triangles are tree-ring sites and solid circles are meteorological stations. Larger symbol sizes indicate lower-value means and more extreme drought

was then calculated to produce the regional MayJune precipitation series. For the purpose of comparison, the 2 series shown in Fig. 5 were normalized to their respective means for the reference period $1955-2005$.

As shown in Fig. 7, the TWI series corresponded well to the regional May-June precipitation variation, especially for the pre-1985 period. After 1985, the discrepancies between the 2 series became larger, and the agreement between the TWI and the precipitation series weakened, especially for relatively wet years. The correlation between the 2 series was 0.513 during the period 1955-2005, which is significant at the 0.01 level. The correlation during the period 1955-1984 was higher at $0.662(\mathrm{p}<0.01)$, while the correlation coefficient for 1976-2005 was only $0.377(p<0.05)$. The weaker correlation during the latter period was mostly caused by large differences in the relatively wet years. Because the sites used to construct the network chronology are moisture-sensitive, tree growth in wet years will become more limited by factors other than moisture conditions. In general, the low-value years in the TWI series matched well with the low-precipitation years in the instrumental data, especially for years with more prominent drought conditions, such as 1962,
1968, 1971, 1974, 1981, 1995 and 2001. This indicated that the TWI series can preserve signals of major regional droughts very well, but it may have a limited ability to record the wet conditions.

In the analysis of regional variability among the individual tree-ring series, the ISC series presented a value of 1.0 for 13 years during the period 1700-2005 (Fig. 6b). Thus, for these 13 years, all individual series indicated the same moisture conditions as the composite series. For all the years with negative TWI values, the mean ISC was 0.72 , suggesting a high level of spatial consistency among the individual series as indicators of drought conditions. Good agreement was observed between the TWI and ISC series with a correlation coefficient of $-0.92(p<0.001)$, suggesting higher spatial consistency for more severe drought events.

\subsection{Frequency and severity of droughts in the Qilian Mountains since 1700}

The result of the 1-sample K-S test shows that by a relatively large margin $(p=0.44)$ the null hypothesis of TWI having a normal distribution cannot be rejected. Therefore, we can assume that the TWI has a 

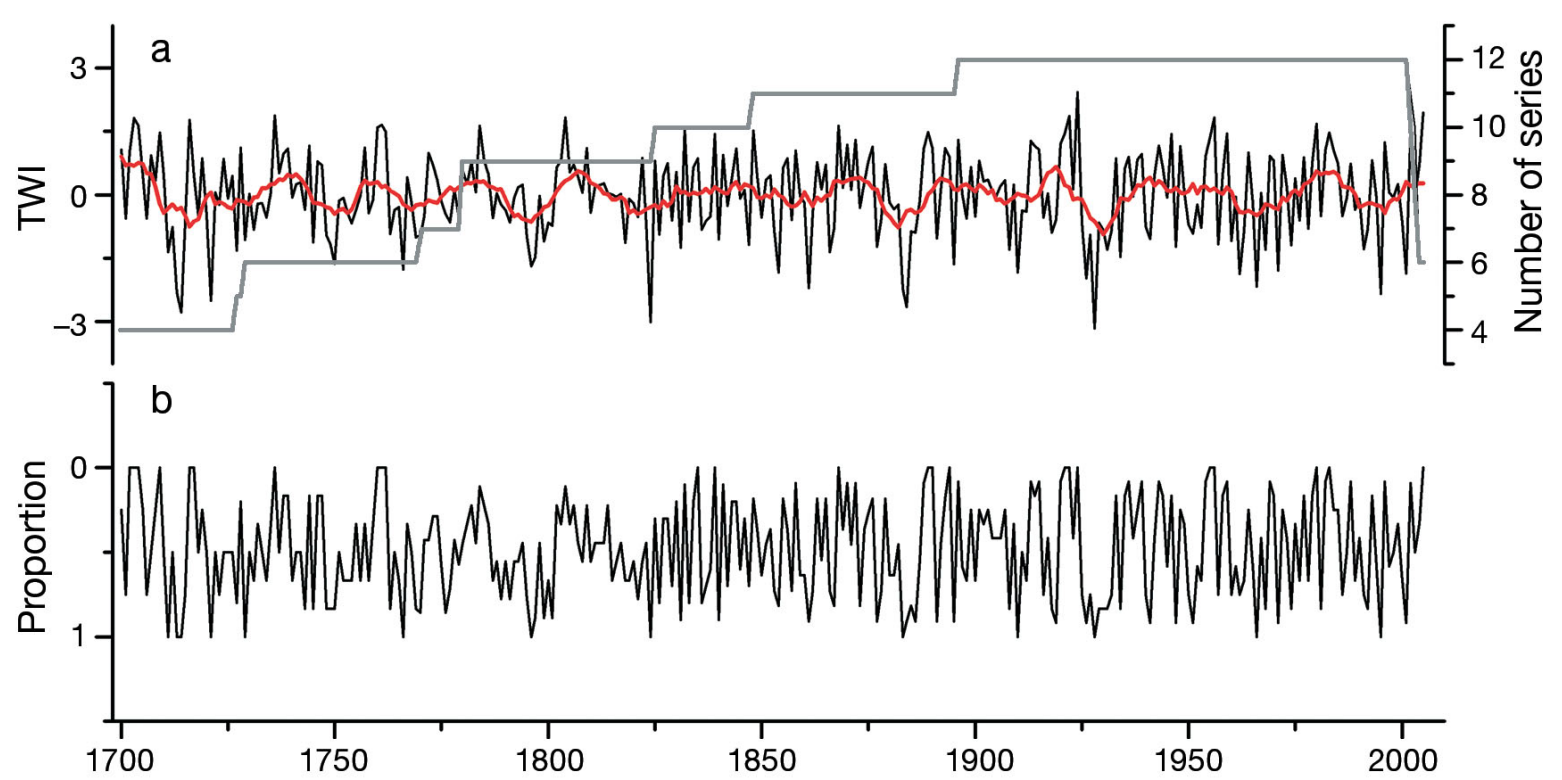

Fig. 6. (a) The regional tree-ring width index master series (TWI) and sample depth as the number of series. The black line shows annual values and the red line represents $11 \mathrm{yr}$ moving averages. The gray line shows the number of series available in different periods. (b) The proportion of the number of the standardized series with negative values from 1700-2005

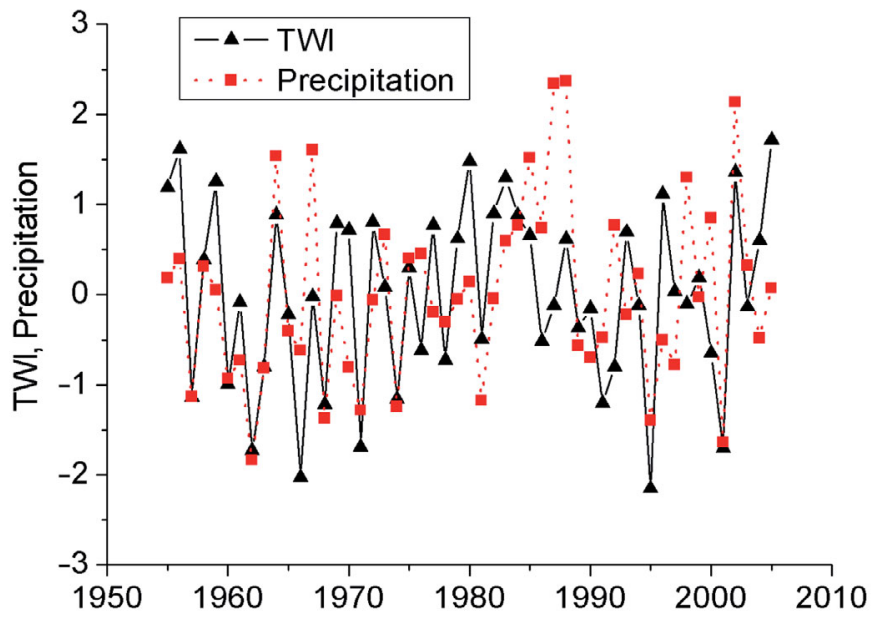

Fig. 7. Comparison between the standardized tree-ring width index master series (TWI) and standardized mean May-June precipitation at 13 meteorological stations during 1955-2005

near-normal distribution and classify the TWI series to reflect different levels of drought severity. According to this classification, we identified 98 drought years for the study period 1700-2005 (Table 4, Fig. 8a). Among these years, there were 5 extreme drought years $(1714,1721,1824,1884$ and 1928) as well as 78 moderate and 15 severe drought years. Based on examination of $30 \mathrm{yr}$ moving windows (Knight et al. 2010), a minimum of 6 droughts might occur in each $30 \mathrm{yr}$ period. Moreover, there was a high drought frequency during the period 19241954, whereas the drought frequency during the period 1714-1765 was low (Fig. 8b).

We further examined the timing of droughts based on their different severities and the intervals since the previous drought years. The intervals between drought years were usually short with recurrence being observed in the next year or 1 to 2 yr thereafter (Table 4). However, there was one period (18021817) in which more than $10 \mathrm{yr}$ elapsed between drought years. Severe and extreme droughts were associated with an average interval of $16 \mathrm{yr}$, but they often occurred during persistent dry periods. The drought event with the longest duration occurred during 1925-1932.

The frequency of drought occurrence was assessed for different severity levels in $50 \mathrm{yr}$ and $100 \mathrm{yr}$ intervals. The occurrence of drought years became more frequent in the first half of the 20th century on a 50 yr timescale, while there were relatively fewer droughts in the 18th and the first half of the 19th centuries (Table 5). On the $100 \mathrm{yr}$ timescale, however, the frequencies of moderate drought years per century increased gradually, and a larger number of severe droughts occurred during the 20th century. Although there was only one extreme drought year in the 20th century, the total number of drought years was the highest among the 3 centuries compared. 
Table 4. Occurrence of droughts in the Qilian Mountains during 1700-2005, indicating the year of occurrence, severity class of the drought $(\mathrm{M}=$ moderate, $\mathrm{S}=$ severe, $\mathrm{E}=\mathrm{ex}-$ treme), and the interval between droughts (i.e. the number drought-free years following the previous drought)

\begin{tabular}{|c|c|c|c|c|c|}
\hline Year & Severity & $\begin{array}{l}\text { Interval } \\
\quad(\mathrm{yr})\end{array}$ & Year & Severity & $\begin{array}{c}\text { Interval } \\
(\mathrm{yr})\end{array}$ \\
\hline 1701 & $\mathrm{M}$ & & 1861 & $\mathrm{~S}$ & 3 \\
\hline 1706 & $\mathrm{M}$ & 4 & 1866 & $\mathrm{M}$ & 4 \\
\hline 1711 & $\mathrm{M}$ & 4 & 1867 & $\mathrm{M}$ & 0 \\
\hline 1712 & $\mathrm{M}$ & 0 & 1877 & $\mathrm{M}$ & 9 \\
\hline 1713 & $\mathrm{~S}$ & 0 & 1878 & $\mathrm{M}$ & 0 \\
\hline 1714 & $\mathrm{E}$ & 0 & 1883 & $\mathrm{~S}$ & 4 \\
\hline 1715 & M & 0 & 1884 & $E$ & 0 \\
\hline 1721 & $\mathrm{E}$ & 5 & 1885 & $\mathrm{M}$ & 0 \\
\hline 1727 & $\mathrm{M}$ & 5 & 1886 & $\mathrm{M}$ & 0 \\
\hline 1729 & $\mathrm{M}$ & 1 & 1891 & $\mathrm{M}$ & 4 \\
\hline 1731 & $\mathrm{M}$ & 1 & 1895 & $\mathrm{~S}$ & 3 \\
\hline 1734 & $\mathrm{M}$ & 2 & 1898 & M & 2 \\
\hline 1745 & $\mathrm{M}$ & 10 & 1900 & M & 1 \\
\hline 1748 & $\mathrm{M}$ & 2 & 1908 & M & 7 \\
\hline 1749 & $\mathrm{M}$ & 0 & 1910 & $\mathrm{~S}$ & 1 \\
\hline 1750 & $\mathrm{~S}$ & 0 & 1916 & M & 5 \\
\hline 1754 & $\mathrm{M}$ & 3 & 1918 & M & 1 \\
\hline 1763 & $\mathrm{M}$ & 8 & 1919 & M & 0 \\
\hline 1766 & $\mathrm{~S}$ & 2 & 1925 & M & 5 \\
\hline 1769 & $\mathrm{M}$ & 2 & 1926 & $\mathrm{~S}$ & 0 \\
\hline 1770 & $\mathrm{M}$ & 0 & 1927 & M & 0 \\
\hline 1771 & $\mathrm{M}$ & 0 & 1928 & $\mathrm{E}$ & 0 \\
\hline 1777 & $\mathrm{M}$ & 5 & 1929 & M & 0 \\
\hline 1779 & $\mathrm{M}$ & 1 & 1930 & M & 0 \\
\hline 1787 & $\mathrm{M}$ & 7 & 1931 & M & 0 \\
\hline 1791 & $\mathrm{M}$ & 3 & 1932 & M & 0 \\
\hline 1795 & $\mathrm{M}$ & 3 & 1934 & M & 1 \\
\hline 1796 & $\mathrm{~S}$ & 0 & 1940 & M & 5 \\
\hline 1797 & $\mathrm{M}$ & 0 & 1941 & M & 0 \\
\hline 1799 & $\mathrm{M}$ & 1 & 1947 & M & 5 \\
\hline 1800 & $\mathrm{M}$ & 0 & 1950 & M & 2 \\
\hline 1801 & $\mathrm{M}$ & 0 & 1951 & M & 0 \\
\hline 1818 & $\mathrm{M}$ & 16 & 1953 & M & 1 \\
\hline 1821 & $\mathrm{M}$ & 2 & 1957 & M & 3 \\
\hline 1823 & $\mathrm{M}$ & 2 & 1960 & M & 2 \\
\hline 1824 & $\mathrm{E}$ & 0 & 1962 & $\mathrm{~S}$ & 1 \\
\hline 1826 & $\mathrm{M}$ & 1 & 1963 & M & 0 \\
\hline 1829 & $\mathrm{M}$ & 2 & 1966 & $\mathrm{~S}$ & 2 \\
\hline 1831 & $\mathrm{M}$ & 1 & 1968 & M & 1 \\
\hline 1833 & $\mathrm{M}$ & 1 & 1971 & $\mathrm{~S}$ & 2 \\
\hline 1836 & $\mathrm{M}$ & 2 & 1974 & M & 2 \\
\hline 1837 & $\mathrm{M}$ & 0 & 1976 & M & 1 \\
\hline 1838 & $\mathrm{M}$ & 0 & 1978 & M & 1 \\
\hline 1840 & $\mathrm{M}$ & 1 & 1981 & M & 2 \\
\hline 1847 & $\mathrm{M}$ & 6 & 1991 & M & 9 \\
\hline 1850 & $\mathrm{M}$ & 2 & 1992 & M & 0 \\
\hline 1853 & $\mathrm{M}$ & 2 & 1995 & $\mathrm{~S}$ & 2 \\
\hline 1854 & $\mathrm{~S}$ & 0 & 2000 & M & 4 \\
\hline 1857 & M & 2 & 2001 & $\mathrm{~S}$ & 0 \\
\hline
\end{tabular}

\subsection{Temporal and spatial evolutions of an extreme drought event}

The drought event that occurred in north China from the late 1920s to the early 1930s has attracted much attention (Li et al. 1994, Xu 1997, Li et al. 2006, Liang et al. 2006). The spatial extent of this multi-year drought event covered the entire region of north and northwest China and part of the People's Republic of Mongolia. Although the this event occurred shortly before the notorious North American dust bowl drought, it is much less well known due to the lack of documentation at the time, when China was plagued by civil wars and a foreign invasion. According to the TWI series, this event was the one with the longest duration during the study period 1700-2005, lasting from 1925 to 1932. However, the spatial structure of this event was not uniform, as can be seen in the variations among the 12 tree-ring sites. Fig. 9 shows that the drought conditions began in the western part of the study region in 1925 and progressed eastward over time. The severity peaked in 1928, when there were nation-wide drought conditions. Afterward, the drought severity abated in the western part of the study region, while drought conditions lingered in central and eastern areas. By 1932, only the central part of the study region was still under drought conditions, and the entire region returned to normal or wet conditions in 1933.

\subsection{Large-scale spatial structure of moisture conditions}

Spatial linkages of the drought conditions in the study region to other regions in East Asia may provide insight into the physical processes associated with drought occurrence. Using cluster analysis, we summarized the spatial characteristics of the moisture conditions in central and eastern China corresponding to the 19 severe and extreme drought years during 1700-2000 recorded in the TWI series (Table 4). We grouped the 19 drought years into 3 clusters with relatively similar spatial structures (Fig. 10):

Pattern I: This pattern represents the largest spatial extent of droughts, covering almost all of central and eastern China.

Pattern II: The droughts in these years occurred mainly in northwestern and southwestern China (provinces of Gansu, Ningxia, Inner Mongolia, Yunnan, Guangxi and Guizhou). The belts of dry and wet conditions running northwest to southeast showed an alternating dry-wet pattern from southwestern China to the northeast. 


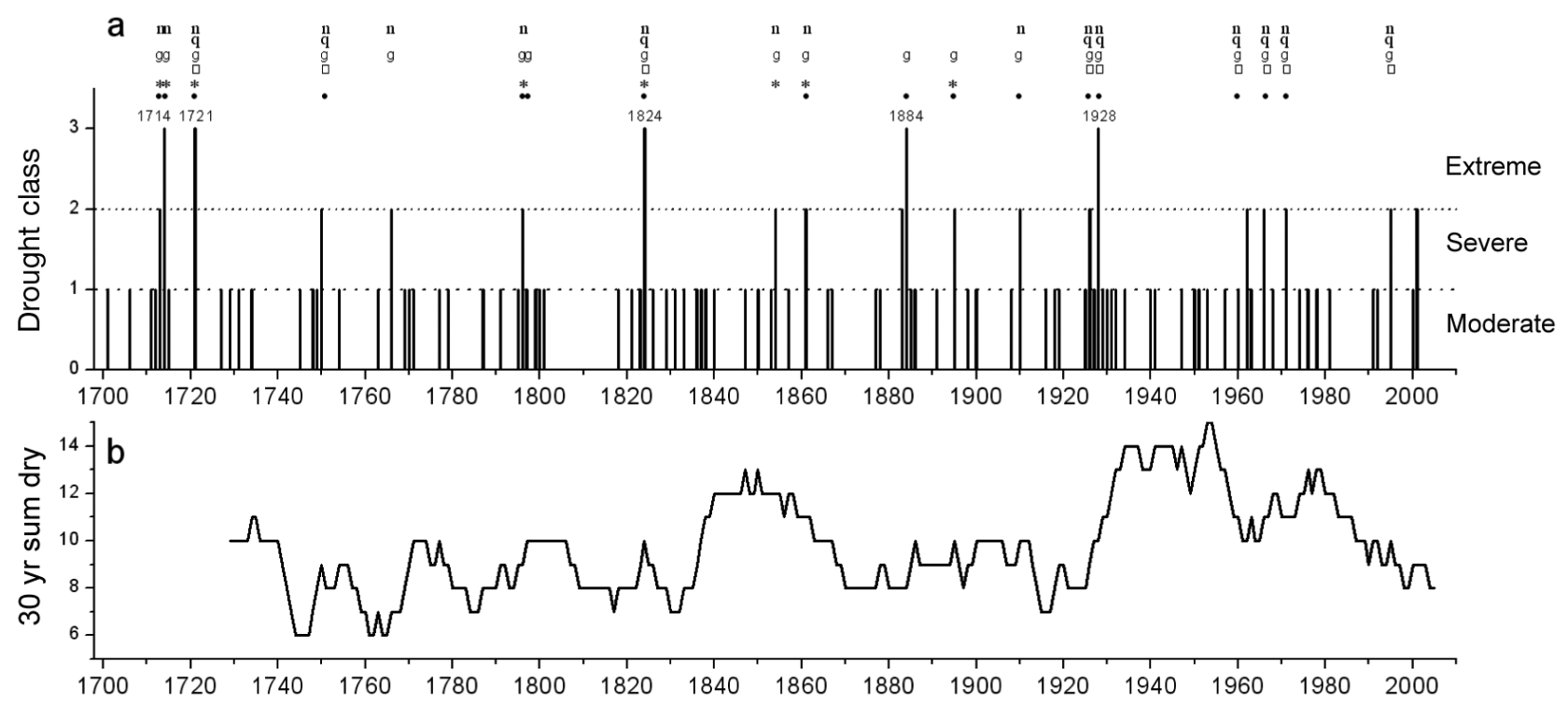

Fig. 8. (a) Occurrence of droughts of different severities (Class 1: moderate; Class 2: severe; Class 3: extreme) based on the regional tree-ring width index master series (TWI). Dates of extreme events are shown. Symbols above lines representing severe and extreme droughts show drought events recorded in these years by different historical documents: (•): CMA (1981); ( $\square$ ): Shi (2003); (*): Zhang (2004); (q, n, g): volumes on Qinghai, Ningxia and Gansu, respectively, in Wen (2005). (b) Number of drought years in the preceding $30 \mathrm{yr}$ moving window (for example, the value in 1730 indicates the number of dry years from 1701 to 1730 )

Pattern III: Other than the droughts in our study area and northern China, droughts occurred mainly in the region south of the Yangtze River, while the region just north of the Yangtze River was wet. The spatial distribution of moisture conditions showed a dry-wet-dry pattern from the southeast to the northwest.

\section{DISCUSSION}

\subsection{Comparisons between tree-ring records and historical documents}

Severe drought events usually have long durations and impact large areas, and therefore they have

Table 5. Frequency (number of years) of droughts of different severities in the Qilian Mountains for $50 \mathrm{yr}$ and $100 \mathrm{yr}$ intervals

\begin{tabular}{|cccccc|}
\hline Interval & Periods & Moderate & Severe & Extreme & Total \\
\hline 50 yr & $1700-1749$ & 12 & 1 & 2 & 15 \\
& $1750-1799$ & 12 & 3 & 0 & 15 \\
& $1800-1849$ & 14 & 0 & 1 & 15 \\
& $1850-1899$ & 11 & 4 & 1 & 16 \\
& $1900-1949$ & 15 & 2 & 1 & 18 \\
& $1950-1999$ & 13 & 4 & 0 & 17 \\
100 yr & $1700-1799$ & 24 & 4 & 2 & 30 \\
& $1800-1899$ & 25 & 4 & 2 & 31 \\
& $1900-1999$ & 28 & 6 & 1 & 35 \\
\hline
\end{tabular}

historically been well documented in China. We reviewed historical documents (CMA 1981, Shi 2003, Zhang 2004, Wen 2005) for evidence of droughts to corroborate those events indicated by the TWI series and found that almost all of the severe and extreme droughts revealed by the TWI series were recorded by the historical documents as occurring in and around the study region (Fig. 8a). Of the 78 moderate droughts, 70 were also recorded in the historical documents; however, the regional coverage was less extensive. In contrast, extreme droughts tended to be recorded by multiple historical documents, reflecting the greater large-scale homogeneity of extreme droughts compared with moderate and severe droughts.

Some differences were also observed between the TWI and the historical documents. For example, according to the TWI series, the droughts that occurred in 1877 and 1878 were moderate in severity, while the historical documents indicated that these were extreme droughts, at least in north-central China, where they were associated with a death toll of more than 10 million people due to famine in Shaanxi, Gansu and Ningxia provinces (Wang 2009). This demonstrates that large-scale drought events may exhibit a variety of spatial structures and the drought severity in one area may not be representative of the entire region impacted by these events. In addition, several droughts in the TWI series were not confirmed by the historical documents. One such example is the period 1883-1884, which was associated 


\begin{tabular}{|c|c|c|c|c|c|c|c|c|c|c|c|c|c|}
\hline & \multicolumn{3}{|c|}{ West } & \multicolumn{6}{|c|}{ Central } & \multicolumn{3}{|c|}{ East } & \multirow{12}{*}{$\begin{array}{l}0:-4<\text { value } \leq-3 \\
0:-3<\text { value } \leq-2 \\
\bullet:-2<\text { value } \leq-1 \\
\bullet:-1<\text { value } \leq 0 \\
0: 0<\text { value } \leq 1 \\
0: 1<\text { value }<2 \\
0: 2<\text { value } \leq 3\end{array}$} \\
\hline YEAR & $\mathrm{JG}$ & $\mathrm{JQ}$ & $\mathrm{QF} 2$ & KGM & KL3 & SDL2 & DYK & DDS3 & $\mathrm{XDH}$ & BGH & HX2 & CLH & \\
\hline 1924 & 0 & 0 & 。 & 0 & 0 & 0 & 0 & 0 & 0 & 0 & 0 & 。 & \\
\hline 1925 & . & • & • & . & . & . & . & . & - & 。 & 。 & 。 & \\
\hline 1926 & • & $\bullet$ & - & • & • & • & • & • & $\bullet$ & . & 。 & - & \\
\hline 1927 & . & . & - & . & - & 。 & . & • & - & 。 & 。 & . & \\
\hline 1928 & • & $\bullet$ & . & $\bullet$ & $\bullet$ & $\bullet$ & • & - & - & • & 0 & - & \\
\hline 1929 & . & 0 & . & . & . & . & . & . & 。 & . & . & • & \\
\hline 1930 & . & . & . & . & 。 & 。 & . & . & • & • & • & • & \\
\hline 1931 & • & . & • & • & 。 & 。 & . & . & • & • & • & • & \\
\hline 1932 & . & 。 & 。 & - & . & . & • & 。 & • & • & . & . & \\
\hline 1933 & . & . & & 。 & 0 & 0 & 。 & 。 & 。 & - & 。 & 。 & \\
\hline
\end{tabular}

Fig. 9. Temporal and spatial evolution of the multi-year drought event during 1925-1932. Columns show tree-ring sampling sites arranged from west to east. $(\bullet)$ Negative tree-ring width index series values, indicating dry conditions. Large circles indicate greater severity of drought. (O) Positive values, indicating wet conditions

with an extreme drought event according to the TWI series. The 500 yr dryness-wetness index dataset (CMA 1981) showed that the moisture conditions during 1883-1884 were normal or wet in the provinces close to our study area; while a moderate drought occurred 1 yr earlier (in 1882) at Zhangye, which is the closest station to the tree-ring sites among the 120 stations in the CMA dataset. A moderate drought was also recorded in the adjacent area of Ningxia, east-central Inner Mongolia, and northern China. Additionally, a treering record for Delingha in Qinghai Province on the southern slope of the Qilian Mountains indicated severe drought conditions in 1884 (Huang et al. 2010), which is partially in agreement with our results.

Comparison between the TWI and the dryness-wetness index record at Zhangye (Fig. 11) indicates good agreement, especially for years of severe and extreme droughts. Based on the $3 \mathrm{yr}$ moving average series, 2 distinct dry periods were recorded in both series (approximately in the 1710s and 1920s), along with 2 wet periods (approximately in 1880-1900 and the 1980s). We found that 34 out of all 56 droughts recorded in Zhangye are represented in the tree-ring data $(60.7 \%)$ and 10 out of the 16 severe droughts are recorded $(62.5 \%)$. These agreements confirmed the reliability of the drought signals in the TWI series.
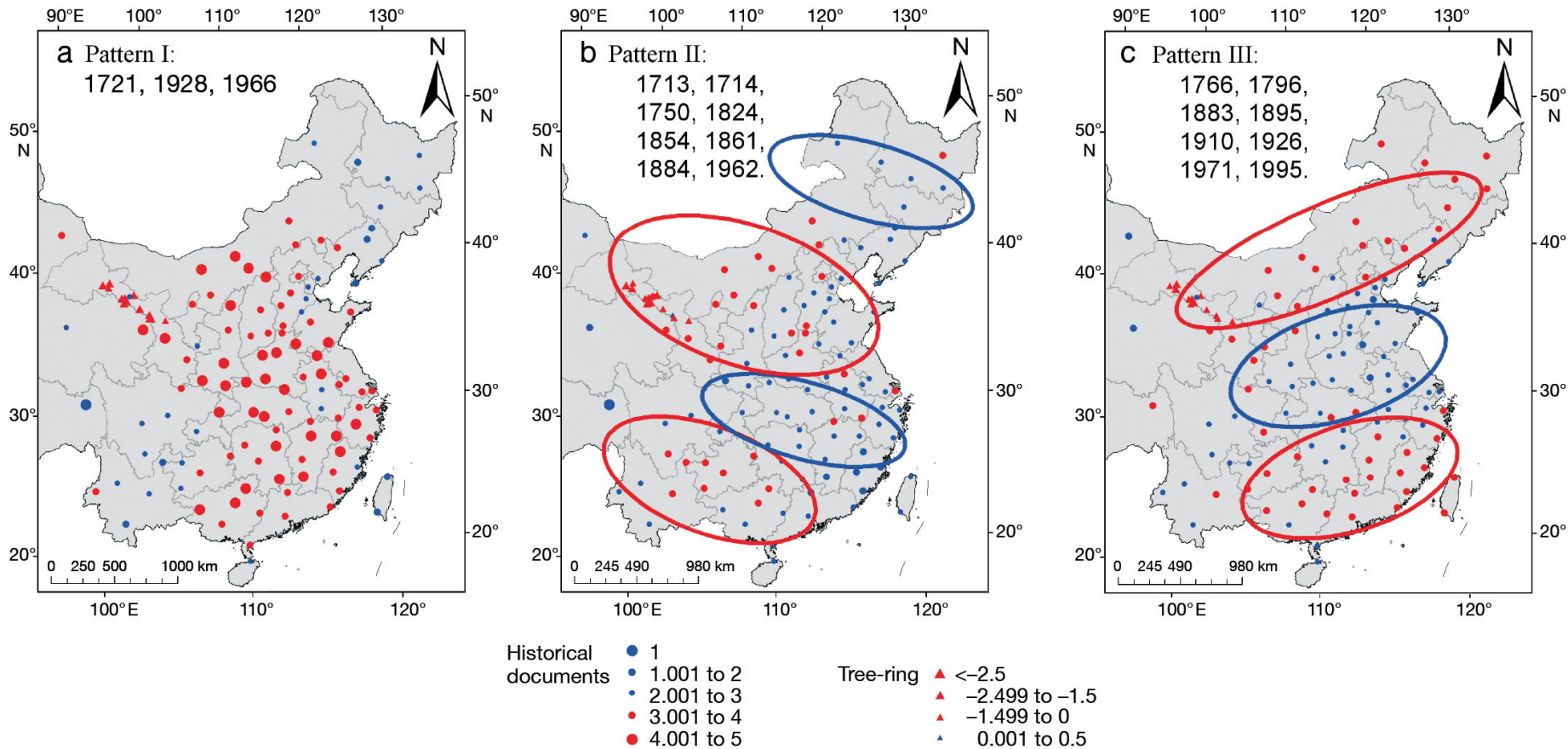

Fig. 10. Spatial patterns of the moisture conditions across central and eastern China during 19 major drought years between 1700 and 2000. Patterns I-III shown in diagrams (a)-(c) respectively were identified by cluster analysis. Triangles are tree-ring sites, and solid circles are the stations in the dryness-wetness index dataset (CMA 1981, Hao et al. 2009). Red and blue colors indicate dry and wet conditions, respectively, with larger symbol sizes representing more extreme conditions. The composite index values represented by the size of the symbols were calculated for each of the 91 stations/locations as the means of the years included in each cluster 


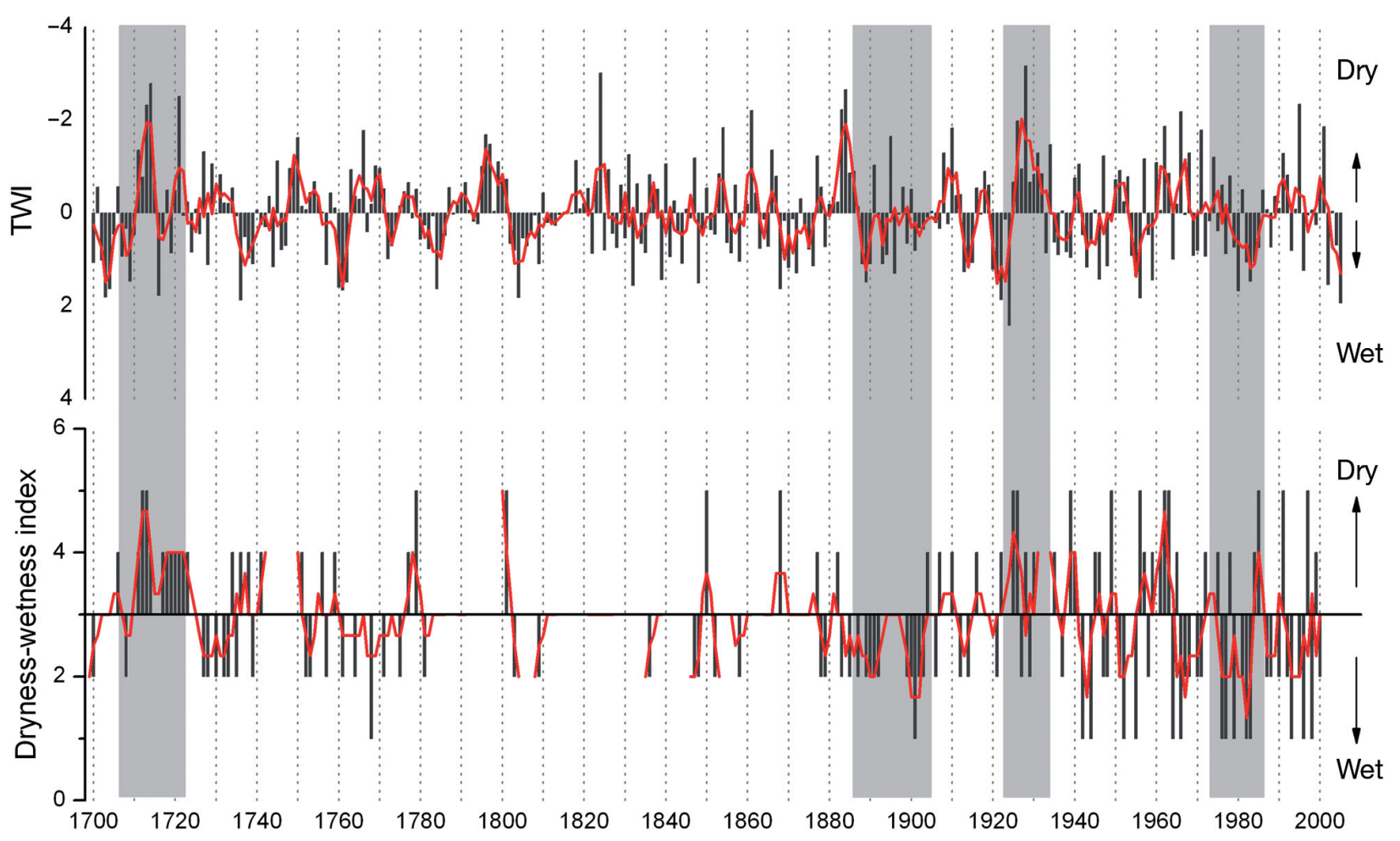

Fig. 11. Comparison between the tree-ring width index master series (TWI) (top) and the dryness-wetness index series at Zhangye (bottom). Black bars show annual values; red lines indicate the 3 yr moving averages; shaded areas are examples when the moisture conditions in both smoothed series are well matched

Discrepancies between the 2 series were also noticed for several periods (e.g. 1720-1740, 1740-1880, and the 1990s), for which, however, good explanations can be found. From 1740-1880, there are several gaps in the historical documents. Although Chinese historical documents are well known for their continuity and completeness, it is inevitable that gaps will exist due to interruptions of civil services caused by wars and shifts of power in central and/or local governments. With respect to climatic information, the TWI series represents the moisture conditions within the tree-ring network, which extended for approximately $500 \mathrm{~km}$ across the study region, while the dryness-wetness index series at Zhangye mainly reflects local conditions. Additionally, the strong correlation between the TWI and regional May-June precipitation indicates that the TWI mainly reflects the moisture conditions during late spring and early summer, i.e. in May and June, whereas the historical documents consider the entire growing season (i.e. May through September). Furthermore, as most of the historical documents in China are focused on the impacts of droughts from the perspective of agricultural production, the recorded moisture conditions may consider water sources other than precipitation, such as irrigation and inter-basin water transfers; this is especially true for Zhangye and its surroundings where melt-water streams are a major source of water supplies for irrigation.

To further confirm the validity of the TWI series, we extracted the summer reconstructed PDSI data at 3 grid points (Points A, B, and C in Fig. 1) from the Monsoon Asia Drought Atlas (MADA) dataset (Cook et al. 2010b) for the period 1700-2005. This dataset is based on tree-ring data and includes sampling sites close to our study region. We found good agreement between the TWI and the 3 PDSI series, with correlation coefficients of 0.423 (Point A), 0.463 (Point B) and 0.374 (Point $C$ ). These results show that the TWI can represent the major characteristics of historical droughts very well, including both their intensity and timing. Thus, tree-ring networks are a good proxy for climate conditions across spatial and temporal scales. This proxy is especially useful in western China, where continuous historical documents are lacking.

\subsection{Possible linkages between regional droughts and atmospheric circulations}

The causes of droughts in China are very complex. Multiple causes are often associated with region- 
wide severe drought events. These include monsoon intensity (e.g. Qian et al. 2007, Ding et al. 2008, Cook et al. 2010a), El Niño Southern Oscillation (ENSO) (e.g. Feng \& Hu 2004, Tong et al. 2006) and other tropical sea surface temperature forcing mechanisms, and continental-scale snow cover (e.g. Ding et al. 2009, Immerzeel \& Bierkens 2010, Yim et al. 2010). The 3 spatial patterns of moisture conditions in central and eastern China provide additional information regarding the possible linkages between regional droughts and atmospheric circulation.

Central and eastern China is recognized as the region that is most influenced by the East Asian summer monsoon, and monsoon intensity can produce distinct regional patterns of precipitation anomalies. For example, a weakened (enhanced) East Asian summer monsoon can cause below-normal (abovenormal) summer precipitation in northern China and above-normal (below-normal) precipitation in the middle and lower reaches of the Yangtze River (MLYR) (Ding et al. 2008). In this study, we examined the values of 4 different monsoon indices (Table 6) for the years with different spatial patterns of moisture conditions identified in Fig. 9 during the instrumental data period. Guo's summer monsoon index (SMI) is based on the mean differences in sea-level pressure fields between land (at $110^{\circ} \mathrm{E}$ ) and sea (at $160^{\circ} \mathrm{E}$ ) in East Asia averaged between $10^{\circ}$ and $50^{\circ} \mathrm{N}$ (Guo 1983); strong monsoon years are associated with large land-sea pressure differences. We calculated Guo's SMI (June-August) for the period 1951-2004, giving a mean value of 1.0 for this period, using NCEP/NCAR Reanalysis data (Kalnay et al. 1996). Li \& Zeng (2002) constructed an East Asian summer monsoon index (EASMI) based on the normalized seasonality of the $850 \mathrm{hPa}$ wind field within the East Asian monsoon domain $\left(10^{\circ}-40^{\circ} \mathrm{N}\right.$ and $\left.110^{\circ}-140^{\circ} \mathrm{E}\right)$. This index is negatively correlated with summer precipitation in the MLYR region. The Indian monsoon index (IMI) is based on zonal wind field differences at the $850 \mathrm{hPa}$ level between 2

Table 6. Monsoon index values for the events of different spatial patterns in Fig. 8 during the instrumental data period. See Section 3.5 for descriptions of spatial patterns and Section 4.2 for full names of monsoon indices

\begin{tabular}{|lrlrrrr|}
\hline $\begin{array}{l}\text { Spatial } \\
\text { pattern }\end{array}$ & Year & SMI & EASMI & IMI & WNPMI & WYMI \\
\hline Pattern I & 1966 & 1.18 & -0.739 & -1.195 & -1.133 & -0.453 \\
Pattern II & 1962 & 1.39 & 0.655 & -1.050 & 0.165 & -0.850 \\
Pattern III & 1971 & 0.94 & -0.868 & 0.173 & -0.244 & 0.058 \\
& 1995 & 0.68 & -1.240 & -0.694 & -1.367 & -0.535 \\
& & & & & & \\
\hline
\end{tabular}

regions: the tropical Indian Ocean and northern India (Wang \& Fan 1999); whereas the western North Pacific monsoon index (WNPMI) is based on the 850 $\mathrm{hPa}$ wind field differences between the region from the southern Indo-China Peninsula to the Philippines and another region including subtropical eastern China and the East China Sea (Wang et al. 2001). Finally, the Webster and Yang monsoon index (WYMI), which is considered to represent a broad measure of the South and Southeast Asian monsoon intensity, is based on differences between the zonal wind fields at the 850 and $200 \mathrm{hPa}$ levels from tropical eastern Africa to the Indochina Peninsula (Webster \& Yang 1992). All of these indices, except for Guo's SMI, are normalized with large positive values indicating strong monsoon intensities.

Because we are limited by the sample size available, as there are only one or 2 cases since 1948 in each weather event category, we can only employ a case-study approach for comparison with the values of the monsoon indices. Pattern I represents nationwide severe droughts, including the years 1721, 1928, and 1966, all of which have been mentioned as extreme or exceptional drought events in previous studies (Zheng et al. 2006, Shen et al. 2007). For the Pattern I event during the instrumental data period (1966), the SMI presented a near-normal value, while all of the other monsoon indices were negative, suggesting weak intensities for all components of the Asian monsoon system. Apparently, the reduced overall monsoon intensity limited the transport of moisture from the surrounding oceans to the entire region and caused large-scale drought events.

Both Pattern II and Pattern III show sub-regional connections between the occurrence of severe droughts in the Qilian Mountains region and other regions in central and eastern China. For Pattern II, using 1962 as an example, SMI indicates a strong monsoon year and EASMI is also positive. Under these conditions, the monsoon rain belt pushed farther north than normal, well into northeast China. Additionally, a weak Indian monsoon and generally weak monsoon intensity in southern and southeastern Asia limited precipitation in south and southwest China. Qian et al. (2007) proposed a conceptual wave-train model to explain the wet-dry spatial pattern of precipitation anomalies in eastern China as the product of the monsoon circulation in combination with westerlies. The interactions between the East Asian monsoon and westerlies generate 4 eastwest running dry-wet zones from south to north, matching the alternating pattern of wet and dry zones in our Pattern II category almost exactly. 
In Pattern III, the MLYR and Huaihe River region experienced wet conditions while drought conditions occurred in the regions to the north and south. Both the SMI and EASMI suggest a weakened East Asian monsoon in 1971 and 1995, while the other components of the Asian monsoon system were close to normal in 1971, but relatively weak in 1995. Yu \& Lin (2007) considered this pattern to be one of the 2 spatial patterns associated with flooding events in the MLYR region. They analyzed the $500 \mathrm{hPa}$ composites of multiple years for the period 1951-2004 and identified the corresponding circulation pattern. When this pattern occurred, the South China Sea high was merged with the northwest Pacific high and formed a strong high-pressure system in the South and East China Seas that directed warm and humid airflows to eastern China. At the same time, cold air originating from a deepened trough over the Ural Mountains, formed in connection with the development of Okhotsk blocking, invaded China from the northwest, and met the warm and humid air in the MLYR and Huaihe River region, forming a persistent rainy belt running in a SW-NE direction, whereas the areas to the north and south of this belt received below normal precipitation.

It is also important to consider the influence of the anomalous westward extension and northward movement of the North Pacific subtropical high. Previous studies have found that droughts (floods) generally occur over northern China (the MLYR) when the position of the subtropical high is farther east and/or south (west and/or north) than normal (Bi 1990, Ding 1991, Wang et al. 2000). Therefore, the locations and orientations of the dry and wet areas in eastern China are expected to have resulted from the combined effects of the strength of the East Asian summer monsoon and/or the position of the North Pacific subtropical high (Qian et al. 2002, Nan \& Li 2003, Guo et al. 2004, Chou et al. 2009, Yu et al. 2009).

As an important ocean-atmosphere coupled phenomenon, ENSO has been considered as representing one of the major causes of droughts and floods in China in various regional studies. However, its effects are both spatially and temporally inconsistent (Feng \& Hu 2004, Tong et al. 2006). We examined the relationship between the TWI and an annually resolved 1100 yr reconstruction of the ENSO variation (Li et al. 2011) for 1700-2005. We found that the composite mean of the ENSO record was close to 0, or neutral conditions (ENSO $=0.069$ ), for the 20 severe and extreme drought years in the TWI. Additionally, cross-correlation analysis between TWI and the ENSO record did not render any statistically significant relationships when the year lagged from 0 to $7 \mathrm{yr}$. This indicates that the relationship between drought occurrence in our study region and ENSO events, if any, may be very complex and that many factors other than ENSO affect the drought pattern in East Asia. For example, some researchers have suggested possible influences of middle- and high-latitude circulation patterns on precipitation in the Qilian Mountains (Liu et al. 2009, Zhang et al. 2009, Zhao et al. 2011).

We can conclude that some historical droughts in the Qilian Mountains have been associated with severe drought events across all of central and eastern China and are related to the Asian summer monsoon intensity, while others might be regional or isolated local events related to the westerlies or other factors. It should be noted that the above discussion does not provide an exhaustive and comprehensive synthesis regarding the spatial patterns of moisture conditions in central and eastern China. Instead, our intention is to establish largescale spatial linkages between severe drought events in the Qilian Mountains with other regions in China to aid in understanding the complex forcing mechanisms associated with major drought events.

\section{CONCLUSIONS}

Using a network of 12 moisture-sensitive tree-ring series, a regional ring-width index series in the Qilian Mountains of the northeastern Tibetan Plateau was developed. Based on comparison with instrumental data, the ring-width data could accurately capture the spatiotemporal characteristics of the major past droughts in the study region. This dataset was then used to analyze the temporal and spatial characteristics of droughts during the period 17002005. We found that 98 drought years had occurred during the period 1700-2005, with reoccurrence of a drought event often being observed 1 to 2 yr thereafter. Among these drought years, 15 were ranked as severe and 5 as extreme in our classification. During the 20th century, the occurrence of moderate and severe droughts became more frequent in comparison to the 18th and 19th centuries. The tree-ring network effectively displayed the evolution process of the extreme drought event in the late 1920s to early 1930s, showing a progressive pattern from west to east in our study region for both the onset and termination of this event. 
Through comparisons with the historical documents and instrumental data, we found that the regional tree-ring network could provide continuous drought histories and represent the characteristics of severe droughts well, including the frequency, intensity and impact areas of these droughts. Three spatial patterns were identified for the 19 severe and extreme drought years in central and eastern China during 1700-2000. It was found that some of the major droughts recorded by the tree-ring network represent large-scale events, including a few that influenced the entire country, while others were clearly regional or local events with only a limited spatial coverage. It is also of note that there were spatial patterns of moisture conditions that showed the linkages or teleconnections between different parts of the country during these drought years. This finding requires further evaluation through reconstruction of the associated atmospheric circulation patterns in order for the mechanisms that produced these spatial patterns to be fully understood.

Acknowledgements. This research was funded by National Key Technology R\&D Program in the 11th Five-year Plan of China (No. 2007BAC29B02), China Global Change Research Program (No. 2010CB950101), and University of San Diego (FRG \#10-11). We sincerely thank S. W. Leavitt, S. Helama, H. Zhu, T. Pan and P. Xu for their great help.

\section{LITERATURE CITED}

Barber V, Juday G, Finney B (2000) Reduced growth of Alaska white spruce in the twentieth century from temperature-induced drought stress. Nature 405:668-673

Bi M (1990) Features and causes of droughts in Northern China in recent 40 years. In: Ye D, Huang $\mathrm{R}$ (eds) Advances in the disastrous climate research series. China Meteorological Press, Beijing, p 23-32

> Carnelli AL, Theurillat JP, Madella M (2004) Phytolith types and type-frequencies in subalpine-alpine plant species of the European Alps. Rev Palaeobot Palynol 129:39-65

Chou C, Huang LF, Tseng L, Tu JY, Tan PH (2009) Annual cycle of rainfall in the western North Pacific and East Asian sector. J Clim 22:2073-2094

CMA (China Meteorological Administration) (1981) Yearly charts of dryness/wetness in China for the last 500-year period. China Cartographic Publishing House, Beijing

CMA (2003) Ground meteorological observing standards. China Meteorological Press, Beijing

Conover WJ (1971) Practical nonparametric statistics. John Wiley \& Sons. New York, NY, p 295-301

Cook ER (1985) A time-series analysis approach to tree-ring standardization. PhD dissertation, University of Arizona, Tucson, AZ

> Cook ER, Woodhouse CA, Eakin CM (2004) Long-term aridity changes in the western United States. Science 306:1015-1018

Cook ER, Anchukaitis KJ, Buckley BM, D'Arrigo RD, Jacoby
GC, Wright WE (2010a) Asian Monsoon failure and megadrought during the last millennium. Science 328: 486-489

Cook ER, Anchukaitis KJ, Buckley BM, D'Arrigo RD, Jacoby GC, Wright WE (2010b) Monsoon Asia drought atlas (MADA). IGBP PAGES/World Data Center for Paleoclimatology, Data Contribution Series \# 2010-037. NOAA/ NCDC Paleoclimatology Program, Boulder, CO

> Dezfuli A (2011) Spatio-temporal variability of seasonal rainfall in western equatorial Arica. Theor Appl Climatol 104:57-69

Ding Y (1991) Monsoons over China. Kluwer Academic Publishers, Dordrecht

> Ding YH, Wang ZY, Sun Y (2008) Inter-decadal variation of the summer precipitation in East China and its association with decreasing Asian summer monsoon. Part I: Observed evidences. Int J Climatol 28:1139-1161

> Ding Y, Sun Y, Wang Z, Zhu Y, Song Y (2009) Inter-decadal variation of the summer precipitation in China and its association with decreasing Asian summer monsoon. Part II: Possible causes. Int J Climatol 29:1926-1944

> Dracup JA, Lee KS, Paulson EG Jr (1980) On the definition of droughts. Water Resour Res 16:297-302

Fang K, Gou X, Chen F, Li J and others (2010) Reconstructed droughts for the southeastern Tibetan Plateau over the past 568 years and its linkages to the Pacific and Atlantic Ocean climate variability. Clim Dyn 35:577-585

> Feng S, Hu Q (2004) Variations in the teleconnection of ENSO and summer rainfall in northern China: a role of the Indian summer monsoon. J Clim 17:4871-4881

Friedrichs DA, Neuwirth B, Winiger M, Löffler J (2009) Methodologically induced differences in oak site classifications in a homogeneous tree-ring network. Dendrochronologia 27:21-30

Fritts HC (1976) Tree rings and climate. Academic Press, London

> Fu CB, Yu JJ, Zhang YC, Hu SS, Ouyang RL, Liu WB (2011) Temporal variation of wind speed in China for 19612007. Theor Appl Climatol 104:313-324

Gao YX (1962) On some problems of Asian monsoon. In: Gao YX (ed) Some questions about the East Asian monsoon. Science Press, Beijing, p 1-49 (in Chinese)

Gao SY, Lu RJ, Qiang MR, Hasi E, Zhang DS, Chen Y, Xia H (2005) Reconstruction of precipitation in the last 140 years from tree rings at south margin of the Tengger Desert, China. Chin Sci Bull 50:2487-2492

Gou X, Chen F, Cook E, Jacoby G, Yang M, Li J (2007) Streamflow variations of the Yellow River over the past 593 years in western China reconstructed from tree rings. Water Resour Res 43:W06434. doi:10.1029/2006 WR005705

Grissino-Mayer HD (2001) Evaluating crossdating accuracy: a manual and tutorial for the computer program COFECHA. Tree-Ring Res 57:205-221

Guo QY (1983) The summer monsoon intensity index in East Asia and its variation. Acta Geogr Sin 38:207-217 (in Chinese)

Guo Q, Cai J, Shao X, Sha W (2004) Studies on the variation of East-Asian summer monsoon during AD 1873-2002. Chin J Atmos Sci 28:206-215 (In Chinese)

> Hao Z, Zheng J, Ge Q (2009) Variations in the summer monsoon rainbands across eastern China over the past 300 years. Adv Atmos Sci 26:614-620

Holmes RL (1983) Computer-assisted quality control in treering dating and measurement. Tree-Ring Bull 43:69-95 
Huang L, Shao X, Liu H, Wang S and others (2010) A 2800year tree-ring record of severe sustained extreme drought events in Qaidam Basin, Qinghai. Climatic and Environmental Research 15:379-387 (In Chinese)

Immerzeel WW, Bierkens MFP (2010) Seasonal prediction of monsoon rainfall in three Asian river basins: the importance of snow cover on the Tibetan Plateau. Int J Climatol 30:1835-1842

Jain AR, Dubes RC (1988) Algorithms for clustering data. Prentice Hall, Englewood Cliffs, NJ

Kalnay E, Kanamitsu M, Kistler R, Collins W and others (1996) The NCEP/NCAR 40-year reanalysis project. Bull Am Meteorol Soc 77:437-470

Knight TA, Meko DM, Baisan CH (2010) A bimillenniallength tree-ring reconstruction of precipitation for the Tavaputs Plateau, northeastern Utah. Quat Res 73: 107-117

Li J, Zeng Q (2002) A unified monsoon index. Geophys Res Lett 29:1274. doi:10.1029/2001GL013874

> Li J, Gou X, Cook ER, Chen F (2006) Tree-ring based drought reconstruction for the central Tien Shan area in northwest China. Geophys Res Lett 33:L07715. doi: 10.1029/2006gl025803

Li J, Cook ER, D'arrigo R, Chen F, Gou X, Peng J, Huang J (2008) Common tree growth anomalies over the northeastern Tibetan Plateau during the last six centuries: implications for regional moisture change. Glob Change Biol 14:2096-2107

Li J, Cook ER, Chen F, Davi N and others (2009) Summer monsoon moisture variability over China and Mongolia during the past four centuries. Geophys Res Lett 36: L22705. doi: 10.1029/2009GL041162

Li J, Cook ER, Chen F, Gou X, D'Arrigo R, Yuan Y (2010) An extreme drought event in the central Tien Shan area in the year 1945. J Arid Environ 74:1225-1231

Li J, Xie SP, Cook ER, Huang G and others (2011) Interdecadal modulation of El Niño amplitude during the past millennium. Nature Clim Change 1:114-118 (data downloaded from ftp://ftp.ncdc.noaa.gov/pub/data/paleo/ treering/reconstrctions/enso-li2011.txt)

Li W, Cheng X, Liu YD, Xia MF (1994) The top ten natural disasters in modern Chinese history (1840-1949). Shanghai People's Press, Shanghai (in Chinese)

Liang E, Liu X, Yuan Y, Qin N and others (2006) The 1920s drought recorded by tree rings and historical documents in the semi-arid areas of northern China. Clim Change 79:403-432

Liang E, Shao X, Liu H, Eckstein D (2007) Tree-ring based PDSI reconstruction since AD 1842 in the Ortindag Sand Land, east Inner Mongolia. Chin Sci Bull 52:2715-2721

> Liang E, Shao X, Liu X (2009) Annual precipitation variation inferred from tree rings since AD 1770 for the western Qilian Mts., northern Tibetan Plateau. Tree-Ring Res 65: 95-103

> Liang E, Shao X, Eckstein D, Liu X (2010) Spatial variability of tree growth along a latitudinal transect in the Qilian Mountains, northeastern Tibetan Plateau. Can J For Res 40:200-211

Liu W, Gou X, Yang M, Zhang Y, Fang K, Yang T, Jin L (2009) Drought reconstruction in the Qilian Mountains over the last two centuries and its implications for largescale moisture patterns. Adv Atmos Sci 26:621-629

Liu Y, Sun J, Song H, Cai Q, Bao G, Li X (2010) Tree-ring hydrologic reconstructions for the Heihe River watershed, western China since AD 1430. Water Res 44:2781-2792
Morrill C, Overpeck JT, Cole JE (2003) A synthesis of abrupt changes in the Asian summer monsoon since the last deglaciation. Holocene 13:465-476

> Nan S, Li J (2003) The relationship between the summer precipitation in the Yangtze River valley and the boreal spring Southern Hemisphere annular mode. Geophys Res Lett 30:2266. doi:10.1029/2003GL018381

Palmer WC (1965) Meteorological drought. Research Paper No. 45, US Weather Bureau, Washington, DC

> Qian W, Kang HS, Lee DK (2002) Distribution of seasonal rainfall in the East Asian monsoon region. Theor Appl Climatol 73:151-168

> Qian WH, Lin X, Zhu YF, Xu Y, Fu JL (2007) Climatic regime shift and decadal anomalous events in China. Clim Change 84:167-189

Qin C, Yang B, Bräuning A, Sonechkin DM, Huang K (2010) Regional extreme climate events on the northeastern Tibetan Plateau since AD 1450 inferred from tree rings. Global Planet Change 75:143-154

Shao X, Huang L, Liu H, Liang E, Fang X, Wang L (2005) Reconstruction of precipitation variation from tree rings in recent 1000 years in Delingha, Qinghai. Sci China Ser D 48:939-949

Shao X, Wang S, Xu Y, Zhu H, Xu X, Xiao Y (2007) A 3500year master tree-ring dating chronology from the Northeastern part of the Qaidam Basin. Quaternary Science 27:477-485 (In Chinese)

> Shen CM, Wang WC, Hao ZX, Gong W (2007) Exceptional drought events over eastern China during the last five centuries. Clim Change 85:453-471

> Sheppard PR, Tarasov PE, Graumlich LJ, Heussner KU, Wagner M, Österle H, Thompson LG (2004) Annual precipitation since $515 \mathrm{BC}$ reconstructed from living and fossil juniper growth of northeastern Qinghai Province, China. Clim Dyn 23:869-881

Shi G (2003) Natural disasters of Qinghai. Qinghai People's Press, Xining (In Chinese)

St. George S, Meko DM, Girardin MP, MacDonald GM and others (2009) The tree-ring record of drought on the Canadian prairies. J Clim 22:689-710

Stahl K, Demuth S (1999) Linking streamflow drought to the occurrence of atmospheric circulation patterns. Hydrol Sci J 44:467-482

Stokes MA, Smiley TL (1968) An introduction to tree ring dating. University of Chicago Press, Chicago, IL

> Tian Q, Gou X, Zhang Y, Peng J, Wang J, Chen T (2007) Tree-ring based drought reconstruction (AD 1855-2001) for the Qilian Mountains, northwestern China. Tree-Ring Res 63:27-36

> Tong J, Zhang Q, Zhu DM, Wu YJ (2006) Yangtze floods and droughts (China) and teleconnections with ENSO activities (1470-2003). Quat Int 144:29-37

> Touchan R, Xoplaki E, Funkhouser G, Luterbacher J and others (2005) Reconstructions of spring/summer precipitation for the eastern Mediterranean from tree-ring widths and its connection to large-scale atmospheric circulation. Clim Dyn 25:75-98

> Unal Y, Kindap T, Karaca M (2003) Redefining the climate zones of Turkey using cluster analysis. Int J Climatol 23: 1045-1055

Wang X (2009) Study on the great drought of Guangxu's reign in recent three decades. Journal of Institute of Disaster-Prevention Science and Technology 11:110-114 (in Chinese)

- Wang B, Fan Z (1999) Choice of South Asian summer 
monsoon indices. Bull Am Meteorol Soc 80:629-638

Wang S, Ye J, Qian W (2000) Predictability of drought in China. In: Wilhite DA (ed) Drought: a global assessment, Vol I. Routledge, London, p 100-112

- Wang B, Wu R, Lau KM (2001) Interannual variability of Asian summer monsoon: contrast between the Indian and western North Pacific-East Asian monsoons. J Clim 14:4073-4090

Ward JH (1963) Hierachical grouping to optimize an objective function. J Am Stat Assoc 58:236-244

Webster PJ, Yang S (1992) Monsoon and ENSO: selectively interactive systems. Q J R Meteorol Soc 118:877-926

Wen K (2005) Encyclopedia of meteorological disasters in China. China Meteorological Press, Beijing

Wigley TML, Briffa KR, Jones PD (1984) On the average value of correlated time series, with applications in dendroclimatology and hydrometeorology. J Clim Appl Meteorol 23:201-213

Xu GC (1997) Climate change in arid and semi-arid regions of China. China Meteorological Press, Beijing (in Chinese)

Xu CY, Singh VP (2002) Cross comparison of empirical equations for calculating potential evapotranspiration with data from Switzerland. Water Resour Manage 16:197-219

Yang Q, Liu J, Wang Y (2008) Survey report of the National Nature Reserve of Qilian Mountains, Gansu. Gansu Science and Technology Press, Lanzhou (In Chinese)

Yang B, Qin C, Huang K, Fan Z, Liu J (2010) Spatial and temporal patterns of variations in tree growth over the northeastern Tibetan Plateau during the period AD 1450-2001. Holocene 20:1235-1245

Yim SY, Jhun JG, Lu R, Wang B (2010) Two distinct patterns of spring Eurasian snow cover anomaly and their impacts on the East Asian summer monsoon. J Geophys Res 115:D22113. doi:10.1029/2010JD013996

Yin ZY, Shao X, Qin N, Liang E (2008) Reconstruction of a 1436 -year soil moisture and vegetation water use history based on tree-ring widths from Qilian junipers in northeastern Qaidam Basin, northwestern China. Int J

Submitted: February 21, 2011; Accepted: September 11, 2011
Climatol 28:37-53

Yu SQ, Lin XC (2007) Characteristics of two general circulation patterns during floods over the Changjiang-Huaihe River valley. Acta Meteorol Sin 21:366-375

Yu S, Shi X, Lin X (2009) Interannual variation of East Asian summer monsoon and its impact on general circulation and precipitation. J Geogr Sci 19:67-80

Zhang DE (2004) A compendium of Chinese meteorological records of the past 3000 years. Jiangsu Education Press, Nanjing (In Chinese)

Zhang DE (2010) Test of calibration on the paleoclimatic proxy data by using Chinese historical records. Advances in Climate Change Research 6:70-72 (in Chinese)

Zhang QB, Cheng G, Yao T, Kang X, Huang J (2003) A 2326year tree-ring record of climate variability on the northeastern Qinghai-Tibetan Plateau. Geophys Res Lett 30: 1739. doi:10.1029/2003GL017425

Zhang Y, Gou X, Chen F, Tian Q, Yang M, Peng J, Fang K (2009) A 1232-year tree-ring record of climate variability in the Qilian Mountains, northwestern China. IAWA J 30:407-420

Zhang Y, Tian Q, Gou X, Chen F, Leavitt SW, Wang Y (2011) Annual precipitation reconstruction since AD 775 based on tree rings from the Qilian Mountains, northwestern China. Int J Climatol 31:371-381

Zhang YX (2009) The response of Qinghai Spruce (Picea crassifolia) to climate factors since the last half of the 20th century at Qilian Mountains. PhD dissertation, Institute of Tibetan Plateau Research, Chinese Academy of Sciences, Beijing

Zhao LJ, Yin L, Xiao HL, Cheng GD and others (2011) Isotopic evidence for the moisture origin and composition of surface runoff in the headwaters of the Heihe River basin. Chin Sci Bull 56:406-415

Zheng J, Wang WC, Ge Q, Man Z, Zhang P (2006) Precipitation variability and extreme events in eastern China during the past 1500 years. Terr Atmos Ocean Sci 17: 579-592

Proofs received from author(s): November 13, 2011 